\title{
LÍNEA BASE \\ OBJETIVOS DEL MILENIO EN CALDAS ${ }^{1}$.
}

\author{
BOTTOM LINE: \\ MILLENNIUM DEVELOPMENT GOALS IN CALDAS
}

María Eugenia Arango Ospina²

Palabras Claves: Objetivos del Milenio, Pobreza, Metas, Indicadores, Cooperación, Alianzas,

Keywords: Millennium Development Goals, Poverty, Goals, Figures, Cooperation, Alliances

\section{Resumen.}

Definir una agenda mundial en torno a mejorar las condiciones de vida de los más pobres, representó un ideal de solidaridad y cooperación de 189 lideres mundiales presentes en la Cumbre del Milenio celebrada en el año 2000. Las metas cuantificables y con un horizonte temporal al 2015, definidas para avanzar hacia propósitos universales permiten hacer seguimiento para conocer la dinámica, pertinencia y logros alcanzados. Colombia ratifica su compromiso a través del Documento Conpes Social 91, denominado "Metas y Estrategias de Colombia para el logro de los Objetivos del Milenio - 2015". La Línea Base para Caldas, refleja el esfuerzo y compromiso realizado desde diferentes sectores e instituciones por aliviar las condiciones de pobreza y exclusión de un importante grupo de la población y da fe de la existencia en Caldas de suficientes voluntades comprometidas en la construcción colectiva de un proyecto de región que brinde iguales oportunidades a todos.

\section{Abstract}

This paper presents efforts to define a global agenda to improve the living conditions of the world's poorest people. This agenda represented an ideal of solidarity and cooperation of 189 world leaders, who attended the United Nations Millennium Summit held in 2000. The measurable goals set out for the year 2015, defined defines progress towards universal purposes, intends to make a follow-up of the dynamics, relevance and achievements reached. Colombia confirms its commitment by means of the "Social

1 Tomado de la Línea Base de los ODM en Caldas. PNUD - UAM. 2008. Investigador Senior: ARANGO OSPINA Maria Eugenia; Co - investigadores: CASTRILlÓN Patricia; VERGARA Maria del Carmen; GONZÁLES Sandra Julieta; PATINO Orlando de Jesús; PINEDA Jairo; PINEDA Rogelio.

2 Ingeniera Agrónoma. Especialista en Desarrollo Gerencial y Altos Estudios en Desarrollo y Cooperación Internacional; Magíster en Agricultura Ecológica con énfasis en Agricultura Tropical Sostenible; Candidata a Doctora en Desarrollo Globalización y Cooperación Internacional. Directora Centro de Estudios Ambientales y de Desarrollo de la Universidad Autónoma de Manizales; Investigadora Senior de la Línea base de los ODM en Caldas. Coordinadora Cátedra O D M e $\mathrm{n} \quad \mathrm{C}$ a $1 \mathrm{~d}$ a $\mathrm{s}$. mariae.arango@autonoma.edu.co alianza2008m@gmail.com

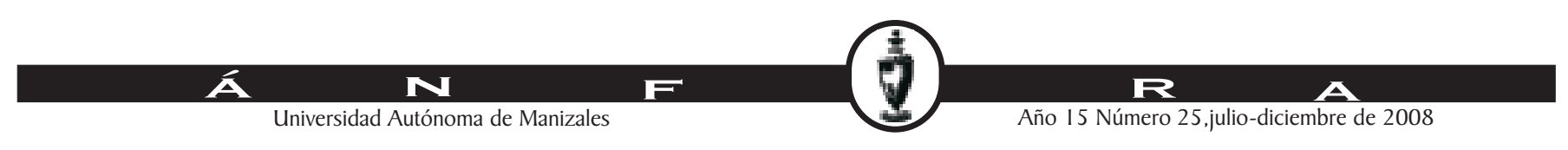


Conpes 91" document called "Colombia's Goals and Strategies to Reach the Millenium Development Goals by 2015." This bottom line shows the effort of many institutions and sectors to try to remedy poverty and marginalizing conditions around an important population group. Also, the document evidences the existence of enough leaders committed to the collective construction of a regional project in Caldas, which can offer equal opportunities to everybody ${ }^{3}$.

\section{Presentación.}

En el 2000, 189 representantes de la Organización de las Naciones Unidas, unen sus voluntades y confirman su compromiso para trabajar en favor de los países menos desarrollados. Los Objetivos de Desarrollo del Milenio (ODM) representan desde entonces, la carta de navegación para construir un mundo, una nación, una región o una localidad con base en criterios de equidad y justicia. Las metas cuantificables y con un horizonte temporal al 2015, definidas para avanzar hacia estos propósitos universales, permiten hacer un seguimiento apropiado para conocer la dinámica, pertinencia y logros alcanzados.

El presente documento es el resultado de una síntesis del trabajo realizado en Caldas sobre la Línea Base de los ODM en Caldas, la cual, si bien hace evidente la necesidad de focalizar las acciones hacia los más pobres y entre estos hacia los pobres rurales, refleja la existencia en Caldas de suficientes voluntades comprometidas en la construcción colectiva de un proyecto de región que brinde iguales oportunidades a todos. Su elaboración parte de la aproximación al contexto socioeconómico, cuya estructura es determinante al analizar la situación del departamento y valorar su avance hacia cada uno de los ODM. Se asumen como metas, aquellas definidas en el documento Conpes Social 91 de 2005, denominado "Metas y Estrategias de Colombia para el logro de los Objetivos del Milenio - 2015". Para finalizar se registran los retos y compromisos para el departamento.

\section{Contexto socioeconómico de Caldas.}

Caldas con $7.888 \mathrm{~km} 2$, esta dividido en 27 municipios distribuidos en seis distritos con una población total de 973.226 habitantes, $2.4 \%$ del total nacional. Manizales, su capital alberga el $40 \%$ de esta, seguida en número de habitantes por Dorada, Riosucio, Chinchiná y Villamaría. Los municipios menos poblados son Marulanda, la Merced, Norcasia, San José y Marmato, cada uno de los cuales no alcanza el $1 \%$ de la población ${ }^{4}$. Su población urbana $(69 \%)$ a pesar de contar con la mayoría de municipios rurales. El total de población urbana en Manizales, La Dorada, Chinchiná, Viterbo y Villamaría es mayor al $80 \%$, aunque 18 de los municipios son en esencia rurales, con más del $80 \%$ de la población rural para municipios como Marmato, Samana y San José5.

La pirámide poblacional registra reducción de las tasas de mortalidad y de fecundidad, aumento de la población mayor y disminución de la infantil. El grupo más importante lo constituyen los menores de 19 años. La reducción de la pirámide en el grupo de 20 a 34 años, evidencia el alto índice de mortalidad en este grupo y el carácter expulsor del departamento. La emigración es creciente, reportada por el $4 \%$ de los hogares; según el número total de casos reportados hasta el 2005, el 19\% emigró antes de 1996, el $29 \%$ entre 1997-2000 y el 52\% entre 2001 y 2005. El 57\% emigran de Manizales, Anserma registra el 8\%, Chinchiná el 7\% y Villamaría 5\%. Los países de destino son en
3 Traducidos por el gestor de traducciones del Instituto de Idiomas de la UAM, Carlos A. Muñoz Torres, Máster en Teoría de la Traducción, Universitat Autònoma de Barcelona. Revisado por Kevin Guzzo, nativo del inglés, estudiante de la Maestría en Traducción de la Universidad Autónoma de Manizales

4 Fuente: Censo 2005 DANE. WWW.dane.gov

5 Ibídem

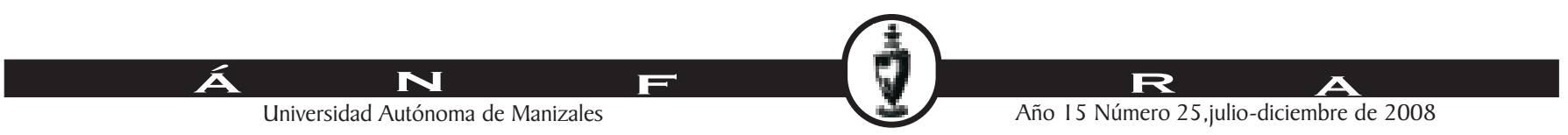


orden de importancia España (40\%), Estados Unidos (33\%), Venezuela (5\%), Ecuador (4\%) y Canadá y Panamá con el $2 \%$ respectivamente. (DANE 2005).

Según las Cuentas Regionales ${ }^{6}$ la participación de Caldas en el PIB nacional entre 19902005 no superó el $2,42 \%$. Por ramas en el 2005, se reporta como principal sector al terciario con $64,64 \%$, seguido del primario con $21,64 \%$, el café con $10,49 \%$, y finalmente el sector industrial con 13,25\%. Manizales genera el $71 \%$ del PIB, Chinchiná el $4,2 \%$, La Dorada 3,3\%, Villamaría 2,2\% y Anserma $2 \%$; con menor participación se ubican Marulanda, Marmato, Victoria, La Merced y Aranzazu?

La población en edad de trabajar (PET) es superior en Caldas que en Colombia, mientras que la tasa General de Participación (TGP) y la Tasa de Ocupación (TO) son inferiores, generando una diferencia importante en la Tasa de Desempleo (TD). Las tasas de desempleo abierto (TDA) y oculto (TDO) son superiores en Caldas, mientras que la Tasa de Subempleo (TS), la I nsuficiencia de Horas (IdH), el Empleo Inadecuado por Competencias (EI PC) y el Empleo Inadecuado por Ingresos (SI PI) son ligeramente inferiores en Caldas en comparación con el total Nacional.

Tabla No1. Indicadores del Mercado Laboral. Caldas Vs. Colombia. 2005

\begin{tabular}{|l|c|c|c|c|c|c|c|c|c|c|}
\hline & $\begin{array}{c}\text { \% } \\
\text { PET }\end{array}$ & TGP & TO & TD & T.D.A & T.D.O & TS & IdH & ElpC & ElpI \\
\hline Caldas & 79,0 & 58,2 & 50,3 & 13,6 & 12,6 & 1,0 & 29,9 & 10,5 & 2,6 & 25,4 \\
\hline $\begin{array}{l}\text { Total } \\
\text { Nacional }\end{array}$ & 76,6 & 59,9 & 52,9 & 11,7 & 10,8 & 0,9 & 31,4 & 11,4 & 3,3 & 25,9 \\
\hline
\end{tabular}

Fuente: Web DANE-Encuesta Continua de Hogares. . Línea Base ODM. Caldas. UAM- CEA. 2008.

A nivel nacional la PET conserva la misma participación porcentual para el período 2000-2005 y equilibrio entre hombres y mujeres, mientras Caldas registra un claro aumento de esta población para el año 2005 con relación al año 2000; esta situación es atribuible al crecimiento vegetativo de la población que aumenta la fuerza laboral presionando este mercado; por sexos la relación es equilibrada. La PET es superior en hombres tanto a nivel nacional como departamental. La Tasa de ocupación femenina en Caldas es sensiblemente inferior a la masculina y se encuentra por debajo de la tasa nacional.

En Índice de Desarrollo Humano (IDH), Caldas está debajo del nacional entre 1993 2005. Por componentes, presenta el puntaje superior en logro educativo 0,85; seguido por el índice de esperanza de vida 0,79 y un PIB de 0,68. EI IDH corregido por desigualdad 1994 -2001 muestra la concentración del ingreso, uno de los factores estructurales que frena el desarrollo, y se ubica entre 11 y 14 puntos por debajo en las series utilizadas.

6 p p rovis i o $n$ a 1 www.dane.gov.co.

7 IRDH Eje Cafetero, PNUDCRECE.2004.

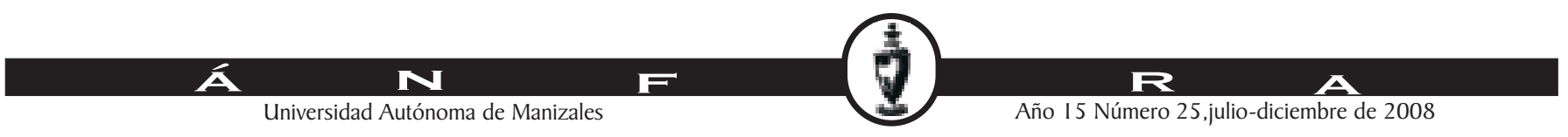




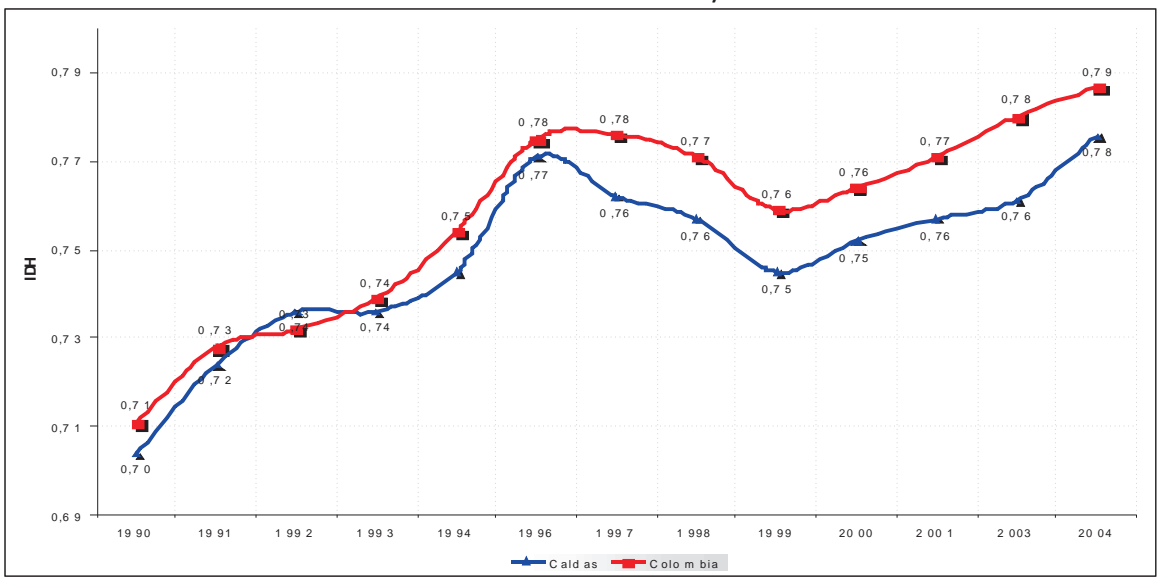

Fuente: Cálculos PNDH, a partir de DANE, Censos de Población; proyecciones de población; Encuesta Nacional de Hogares Cuentas Nacionales; DNP/DDS/GCV. . Línea Base ODM. Caldas. UAM- CEA. 2008.

\section{Caldas frente a los ODM.}

El análisis se presenta para cada uno de los ODM, y se hace énfasis en aquellos casos donde el indicador sea crítico para algunos de los municipios. Se destaca como uno de los propósitos de la elaboración de la línea fue la generación de información pertinente a nivel municipal para ser consideradas en la formulación de los respectivos Planes de Desarrollo Municipales 2008 - 2011.

\section{ODM 1. Erradicar la pobreza extrema y el hambre.}

Las condiciones de vida en Caldas han mejorado en forma sostenida desde 1993 a pesar de la crisis cafetera, con una recuperación más significativa que el promedio nacional. Componentes como capital humano, físico y social han mejorado considerablemente, acercándose en el 2005 al promedio nacional.

Gráfica No2. Índice de Calidad de Vida (ICV).Colombia-Caldas. 1993 - 2005

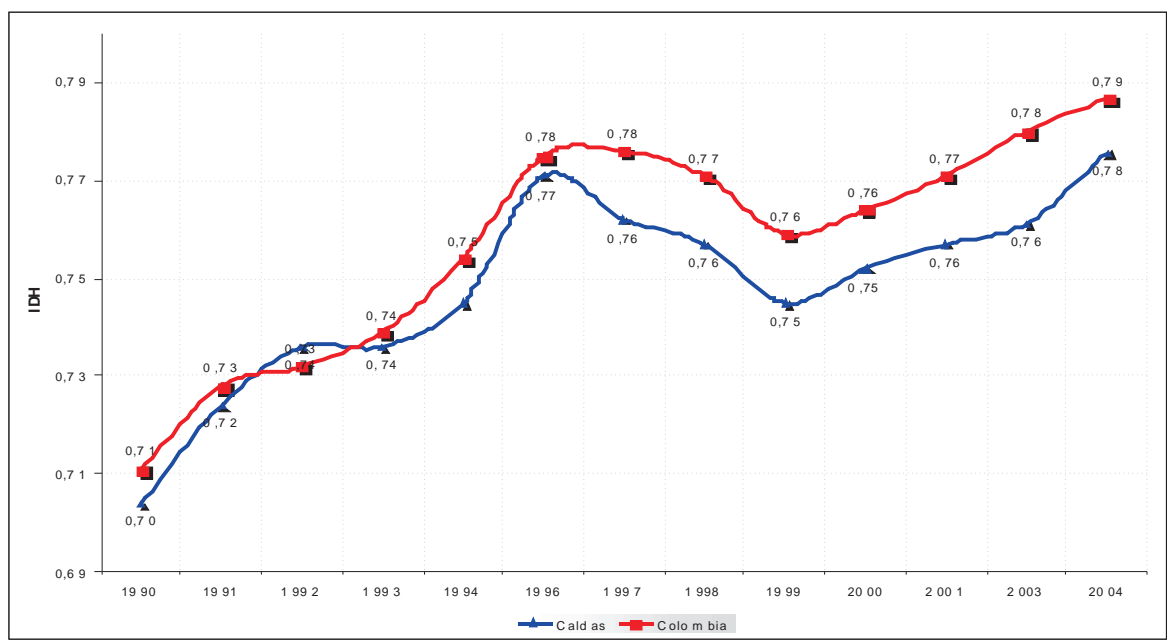

Fuente: Programa Nacional de Desarrollo Humano con base en ECH-DANE.

Línea Base ODM. Caldas. UAM- CEA. 2008.

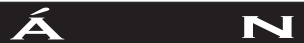

Universidad Autónoma de Manizales 
Por municipios, Manizales presenta a 2003, las mejores condiciones de vida (81.59\%), sin embargo, el departamento registra grandes brechas tanto entre municipios como en la dinámica urbano - rural. Al evaluar los mínimos constitucionales con el indicador $I C V$, municipios con ICV $<67$ son considerados pobres, correspondiendo esta valoración en Caldas a Samana, Pensilvania, Marulanda, Belalcazar y San J osé como se registra en la gráfica.

Gráfica No3. Índice de Condiciones de Vida (ICV). Municipios de Caldas. 2003

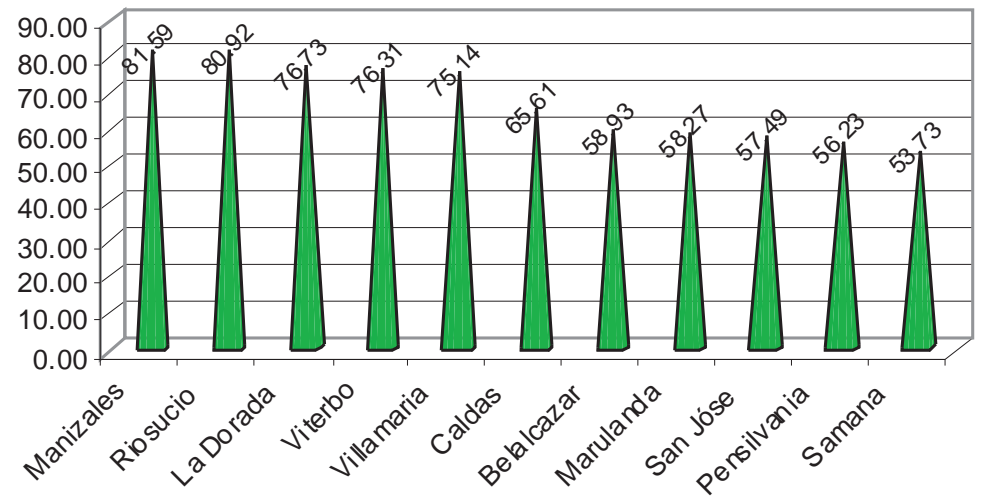

Fuente: Cálculos PNDH con base en SISBEN 2003 actualizado a 2006. Línea Base ODM. Caldas. UAM- CEA 2008.

Aunque las condiciones de pobreza e indigencia disminuyen sistemáticamente en Colombia y en Caldas, la pobreza en Caldas, cercana al $60 \%$ se encuentra por encima de los niveles nacionales; para el caso de la indigencia, aunque menor al promedio nacional hasta el 2004, el comportamiento es estático frente al nacional con mayor dinamismo y reducciones significativas de los porcentajes de población en indigencia a partir del 2004. El número de personas en pobreza para Caldas es de 561.551 y en indigencia $166.422^{8}$ (Gráfica 4)

El hambre como una de las situaciones a enfrentar en situaciones de pobreza y que debe ser abordado desde el ODM 1 se convierte en prioridad para el departamento. Según la "Evaluación Nutricional de los Niños y Niñas Menores de cinco años" al último trimestre de 2004 realizada por la Dirección Territorial de Salud y Confamiliares, los siguientes son los resultados de la situación nutricional por subregiones, donde aparece el Bajo Occidente con los indicadores más críticos para los tres tipos de desnutrición, global, crónica y aguda.

- Desnutrición crónica. La mitad de los niños menores a cinco años del Departamento (49.7\%) tienen un talla correspondiente para su edad; sin embargo, el $16,5 \%$ presenta desnutrición crónica y el $28,8 \%$ está en riesgo de padecerla.

- Desnutrición aguda. $2.6 \%$ de niños menores de cinco años no alcanzan a tener el peso que requieren para la talla, un $11 \%$ se encuentra en riesgo y un $67,9 \%$ tiene
8 Calculo realizado por et equipo investigador con base en el \% de población en pobreza e indigencia sobre el total de la población. CEA-UAM

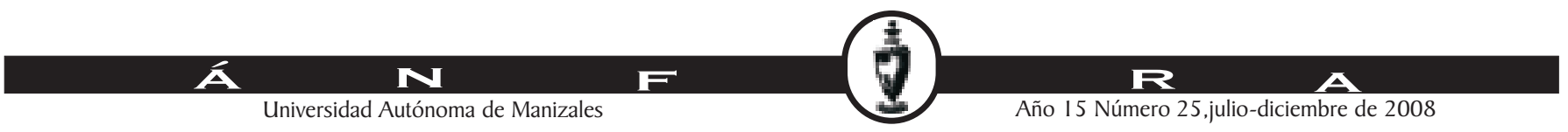


Gráfica No 4. Población en Pobreza e Indigencia. Caldas 2002 - 2006

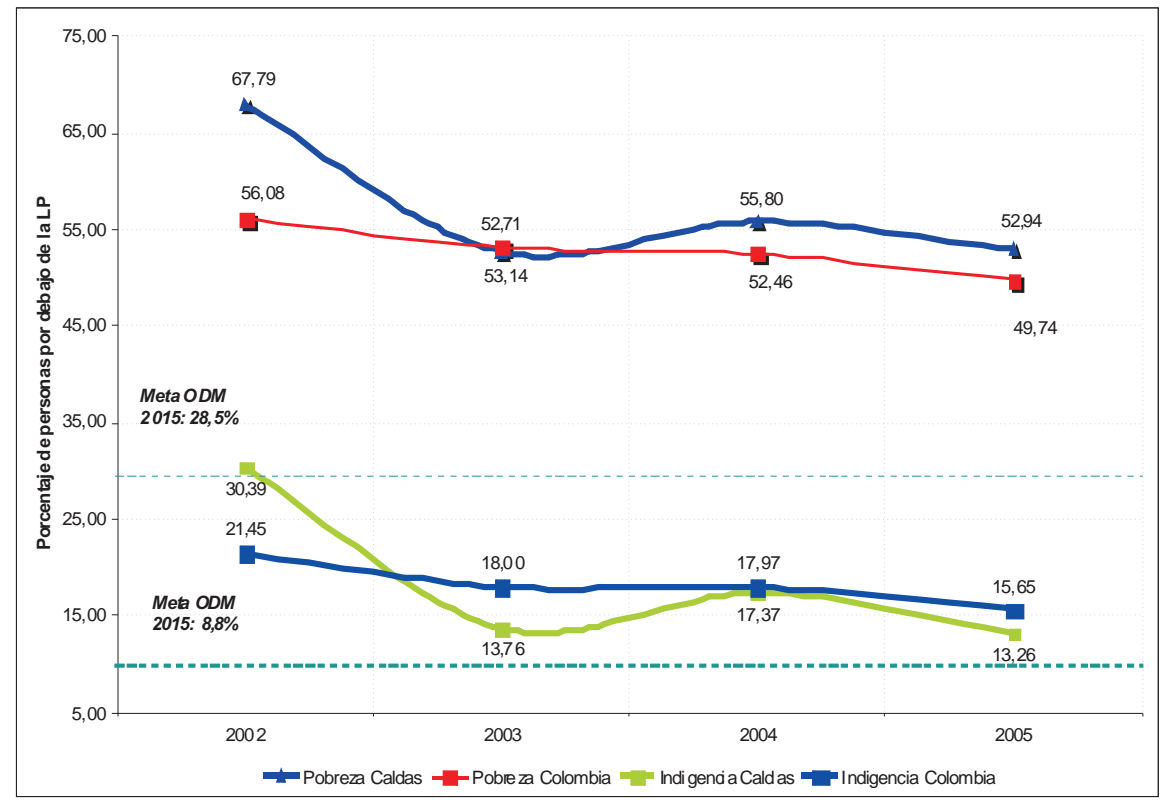

Fuente: MERDP con base en ECH-DANE. Cifra para total nacional con base en ECH tercer trimestre. Las estimaciones para 2003 y 2004 tienen un carácter provisional pues -en materia de ajustes a cuentas nacionales- está basada en las del 2002. Línea Base ODM. Caldas. UAM- CEA. 2008.

condiciones normales. Es necesario prestar atención a los casos de sobrepeso, ya que es una situación que afecta al $12,6 \%$ de estos niños.

- Desnutrición global. Este tipo de desnutrición se presenta cuando los menores de cinco años no tienen el peso respectivo para la edad. El 58.6\% de los niños evaluados se encontraron dentro del rango de normalidad; un $23,3 \%$ en riesgo y el $7,4 \%$ tienen algún grado de desnutrición.

\section{ODM 2. Universalización de la educación básica.}

Caldas, presenta fortalezas institucionales que le permiten evaluar el crecimiento en indicadores de calidad, gestión y cobertura educativa. Proyectos como gratuidad de la educación, educación de adultos, aceleración del aprendizaje, escuela virtual, universalización del preescolar, escuela y café, seguridad alimentaría, aulas paralelas, posprimarias, acceso a banda ancha, familias en acción, bilingüismo y competencias laborales generales y especificas, propenden por favorecer las condiciones de calidad de vida de los estudiantes y mejorar la situación socioeconómica de los núcleos familiares.

Los esfuerzos para mejorar la cobertura en los últimos 4 años han sido fructíferos en todos los niveles escolares ${ }^{9}$. A pesar de rezagarse un poco en 2007, la tendencia es positiva y las tasas de cobertura logradas tanto en preescolar, como en primaria y secundaria, se encuentran por encima de los promedios nacionales. No obstante, la deserción y la repetición deberían convertirse en el patrón determinante de las políticas públicas locales. Las elevadas tasas impulsan a la población a escoger otro tipo de roles en sus planes de vida: Deserción (6.9\%) y repetición (12.35\%)

9 La información de la Secretaria de Educación de Caldas 2007, con base en el censo anual realizado por el DANE a instituciones escolares, muestra una disminución de cupos entre 2005-2006 de 3.876 alumnos, especialmente en preescolar y básica primaria y un aumento en los niveles de secundaria, media y educación de jóvenes y adultos.

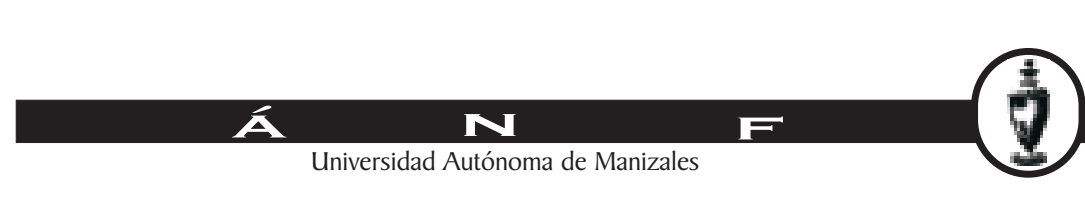


Gráfica No 5. Cobertura Neta por Nivel Educativo. Caldas. 2004-2007

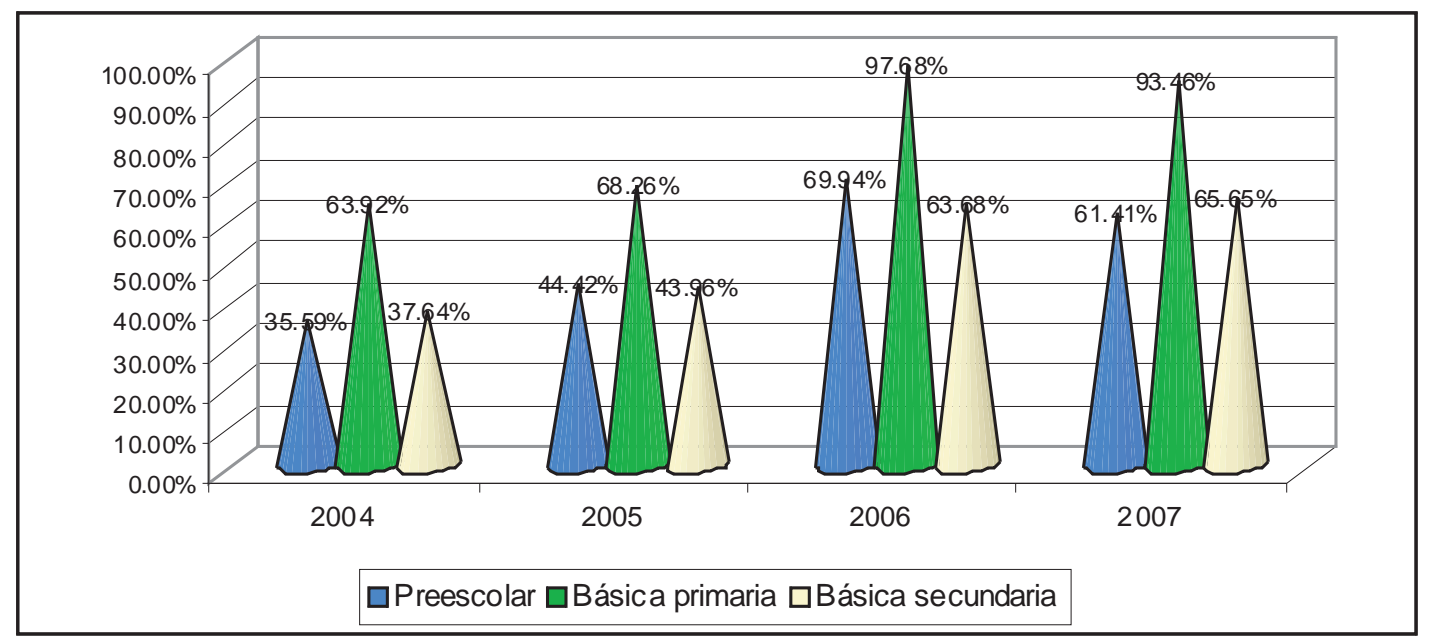

Fuente. Secretaria de Educación del Departamento. 2007. Línea Base ODM. Caldas. UAM- CEA. 2008.

Por municipio se identifican grandes brechas. De un lado, están los municipios destacados en los indicadores educativos impulsando el promedio departamental y del otro, rezagados que lo afectan negativamente, caracterizados estos últimos, por ser los más alejados de la capital en la mayoría de los casos.

- Cobertura neta preescolar ${ }^{10}$. a) Destacados: Riosucio $(88.32 \% 9$, Marulanda (71.67\%), Viterbo (71\%), Villamaría (70\%) y Palestina (70\%); b) Rezagados: La Victoria (42,45\%), Belalcazar (44\%) y Salamina (50\%).

- Cobertura neta primaria ${ }^{11}$. a) Destacados: Riosucio $(125,20 \%)$, Samaná $(114,81 \%)$ y La Victoria (104.11\% ). Rezagados: Neira (71.64\%), San J osé (78.13\% ), Filadélfia (80.64\%).

- Cobertura neta básica secundaria ${ }^{12}$. a) Destacados: Viterbo (88.65\%), Riosucio $(84.66 \%)$ y La Merced $(80.9 \%)$; b) Rezagados: Marulanda $(45.24 \%)$, Norcasia $(48.90 \%)$, Belalcazar (49.03\%), Neira (49.75\%).

- Asistencia escolar niños entre 7 y 11 años ${ }^{13}$. a) Destacados: Manizales (94.1\%), Marmato (95.6\%) y Marquetalia (95.9\%); b) Rezagados: La Dorada (87.7\%) y Riosucio (86.4\%).

- Analfabetismo funcional (mayores de 15 años) ${ }^{14}$. a) Destacados: Riosucio (15\%), Manizales $(17,3 \%)$ y Villamaría $(20 \%)$; b) Rezagados: Samana (35.9\%), Marulanda (33.3\%) y Pácora (32.7\%).

- Analfabetismo en mayores de 15 años $^{15}$ a) Destacados: Manizales (3.3\%), Riosucio (6.9\%), Chinchiná (7\% ) y Villamaría (7\%); b) Rezagados: San J osé (19.7\%), Norcasia $(14,7 \%)$ y Belalcazar $(16,1 \%)$.

10 Secretaría de Educación de Caldas. 2007.

$11 \_2006$.

$12 \_2007$.

13 Cálculos realizados por el PNDH/PNUD con base la encuesta SISBEN de 2003.

14 Ibídem.

15 Cálculos PNDH/PNUD con base en Censo 2005

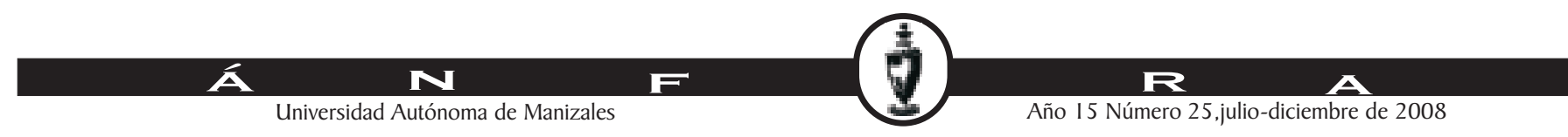


- Escolaridad promedio para el total de la población ${ }^{16}$. a) Destacados: Riosucio $(6,02 \%)$, Manizales $(5,12 \%)$ y Villamaría $(4,93 \%)$; b) Rezagados: Samana $(3,07 \%)$, Marulanda $(3,46 \%)$ y Norcasia ( $3,48 \%)$, Pensilvania (3,53\%).

- Deserción ${ }^{17}$. a) Destacados: Viterbo (3,37\%), Chinchiná (3,56\%) y Manzanares $(3,65 \%)$; b) Rezagados: Norcasia $(22,88 \%)$, Salamina $(12,4 \%)$ y Pensilvania $(11,1 \%)$.

- Repetición ${ }^{18}$. a) Destacados: San José $(5,17 \%)$, Supia $(7,58 \%)$ y Villamaría $(7.99 \%)$; b) Rezagados: Risaralda $(22,45 \%)$, Samaná $(20,67 \%)$ y La Victoria $(19,09 \%)$, Palestina (17.12\%).

Gráfica No 6. Niveles de Asistencia por grupos de edad. Caldas. 2006

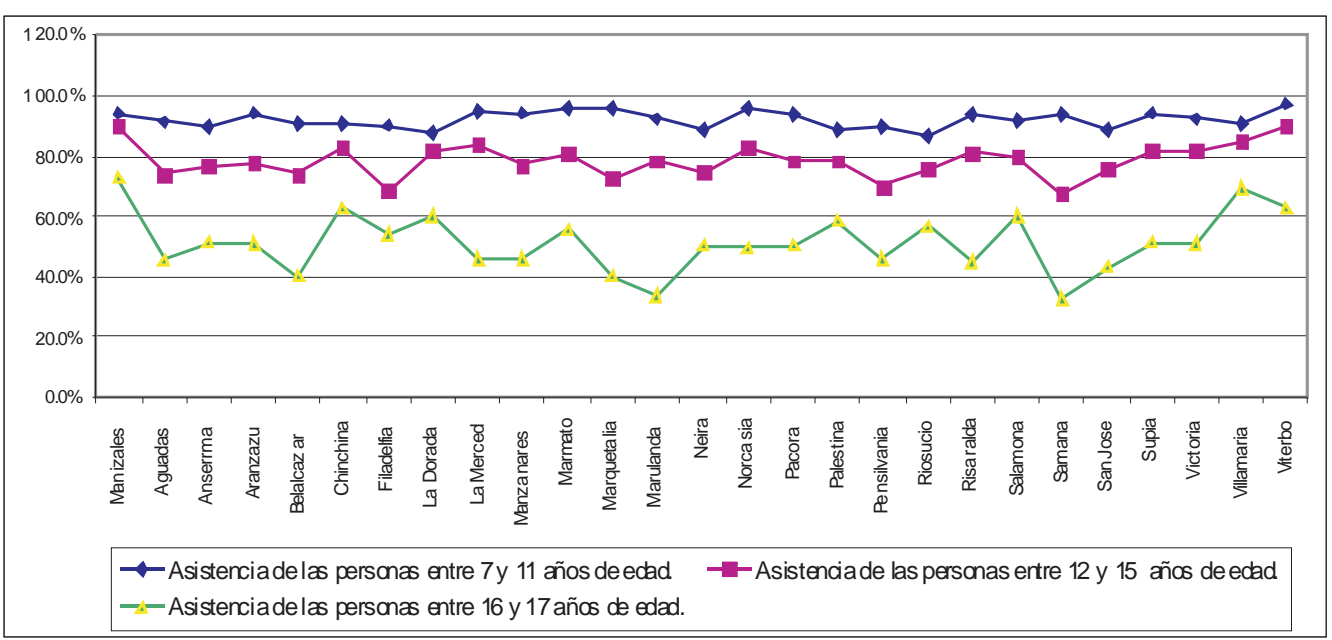

Fuente. Anexo Estadístico ODM Caldas. Información suministrada por PNUD. 2007. Línea Base ODM.

Caldas. UAM- CEA. .2008.

Gráfica No 7. Porcentajes de Aprobación, Deserción y Repetición. Caldas. 2006

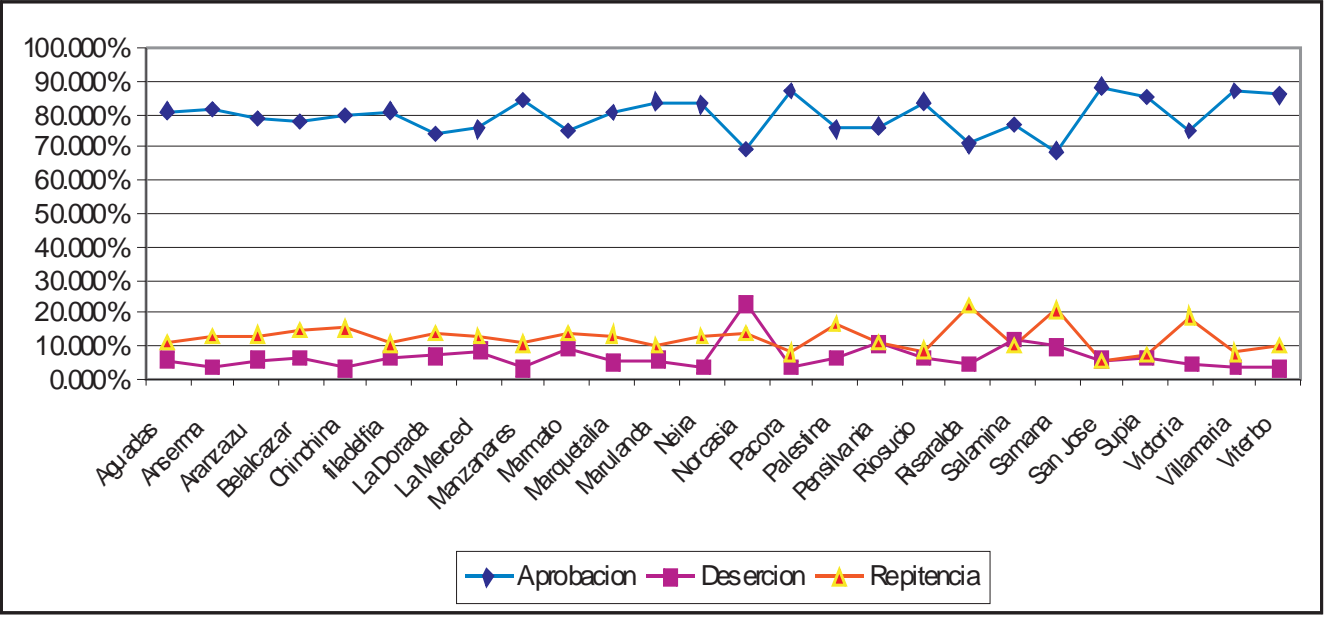

Fuente. Secretaria de Educación de Caldas y de Manizales. 2007. Línea Base ODM. Caldas. UAM - CEA. 2008.
16 Cálculos realizados por el PNDH/PNUD con base la encuesta SISBEN de 2003.

17 Secretaria de Educación del Departamento. 2007.

18 Ibídem.

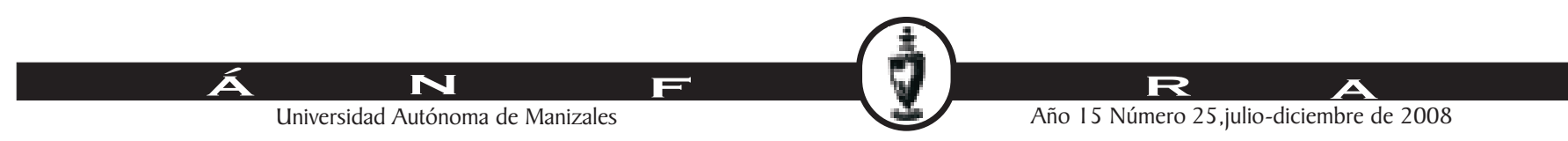


ODM 3. Promover la equidad de género y la autonomía de la mujer.

La meta universal plantea acabar con las desigualdades en educación primaria y secundaria, entre los géneros, preferiblemente para el año 2005, y en todos los niveles antes del 2015, situación no problemática en Colombia. En tal sentido, el análisis para el ODM 3 se realizó para las variables violencia de género e intrafamiliar, mercado laboral y participación política. La dinámica del perfil de la violencia intrafamiliar en Caldas, incluida la violencia de género se realizó a partir de la consulta de los eventos notificados entre 2004 - 2006. En total fueron notificados 4.936 eventos violentos para la zona urbana, frente a 785 notificaciones para el área rural. La mujer, continúa siendo la victima en mayor proporción, con 4.496 notificaciones de agresión, frente a solo 1.237 casos donde el hombre es el agredido. Preocupante que 1.846 casos correspondan a agresión contra menores. El hombre aparece como el mayor agresor, responsable de 4237 casos entre 5696 reportados entre 2004 - 2005, con porcentajes cercanos al $75 \%$ para los tres años analizados; en el $60 \%$ de los casos son empleados, seguidos por el grupo de desempleados y personas dedicadas al hogar con niveles de escolaridad entre primaria y bachillerato para la mayoría de los casos.

La relación esposo / compañero - esposa / compañera es la más recurrente en relación agresor -victima, seguida de la relación madre - hijos con una disminución importante al pasar del $12.9 \%$ en 2004 , al $3.7 \%$ en 2005 y al 3.9\% en 2006 . Es evidente el cambio de roles de agredido a agresor en los hijos e hijas con una dinámica creciente al pasar de $9.9 \%$ en 2004 a $34.2 \%$ en 2005 y $30.5 \%$ en $2006^{19}$. Si bien, la ocupación de la victima corresponde en mayor proporción a aquellas que desempeñan roles en el hogar, es evidente según la información disponible que la independencia económica del agredido no es suficiente para librarse de los eventos violentos. El hallazgo frente a la relación entre el nivel educativo y la calidad de agredido demuestra empíricamente una relación inversa. En forma recurrente el menor número de agresiones se presentó para personas con estudios superiores sea de nivel técnico o profesional; los más altos porcentajes de violencia se presentaron para primaria y secundaria como nivel académico de la victima. La violencia física es más recurrente para los tres años con porcentajes del $55,8 \%, 51,8 \%$ y $48,7 \%$; en segundo lugar se ubica la violencia psicológica con valores de $23,4 \%, 24,8 \%, 27,9 \%$. El factor asociado a los episodios de violencia de mayor recurrencia es el emocional con porcentajes de $43,9 \%, 40,3 \%$ y $44,1 \%$, seguido por los factores socioeconómicos $12,6 \%, 15,1 \%, 14,2 \%$ generadores de estrés y la ingesta de alcohol en porcentajes de $8.9 \%, 12,4 \%$ y $15,3 \%$.

En Manizales, frente a la violencia intrafamiliar según el Sistema de Vigilancia Epidemiológica, para el mismo periodo se notificaron 2642 casos, el $58.4 \%$ relacionado con violencia física, seguida en $30.4 \%$ por violencia psicológica y $5.8 \%$ por violencia sexual. Es importante la identificación de la negligencia y/o descuido por parte de la población como un tipo de violencia frecuente con un $4.7 \%$ de los casos reportados.

Los factores asociados al hecho violento son en orden de importancia: problemas emocionales con porcentajes de $38.3 \%, 60.6 \%, 51.8 \%$ y $56.3 \%$ y socioeconómicos en $12.5 \%, 9.3 \%, 10.2 \%$ y $9.1 \%$ respectivamente. El maltrato conyugal ocupa el $5.8 \%$ de los casos de violencia intrafamiliar y en el $80.3 \%$ de los casos la mujer es la victima y entre este grupo, aquellas entre 25 y 59 años.
19 Dirección Territorial de Salud $\mathrm{d}$ e $\mathrm{C}$ a $1 \mathrm{~d}$ a s. P e r f i Epidemiológico. 2007. sp

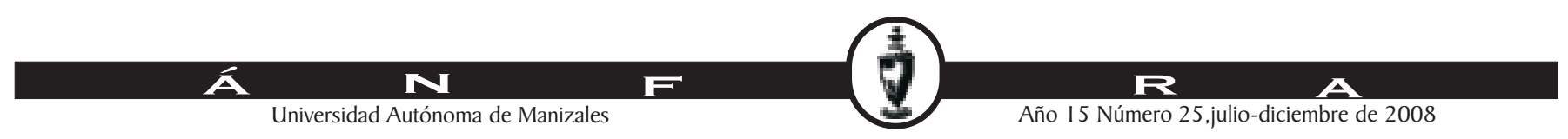


Gráfica No 8. Tipificación de la Violencia. Manizales. 2004-2006

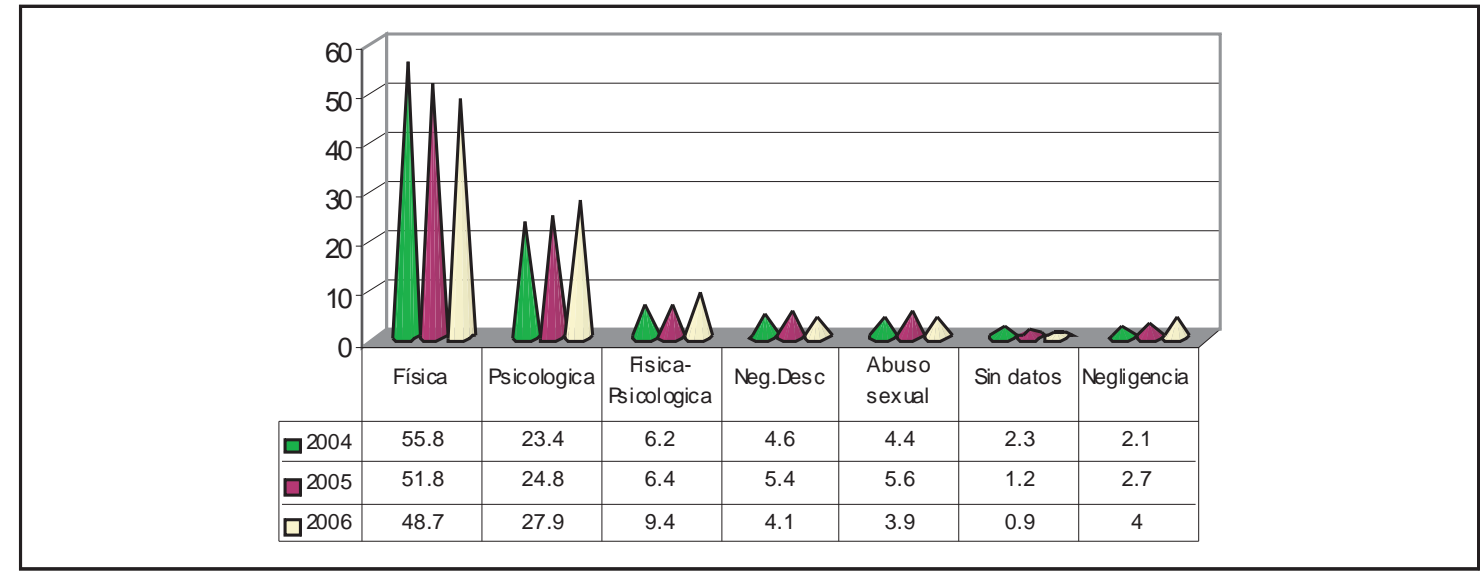

Fuente: Tendencia de la Violencia Intrafamiliar en Manizales. 2003-2006. Sistema de Vigilancia Epidemiológica del Violencia Intrafamiliar. Alcaldía de Manizales. Centro de Atención a la Violencia Intrafamiliar.

Al igual que en Caldas, la mujer continua siendo la victima de la violencia en un alto porcentaje, también aparece un gran porcentaje $(85.5 \%)$ de eventos violentos dirigidos a menores de edad, estudiantes en un $55.1 \%$ y solteras en un $89.9 \%$ de los casos con los hombres como principales agresores, protagonizando el $97.9 \%$ de los casos reportados ${ }^{20}$.

Siguiendo las tendencias de Caldas, el 34\% de las victimas se dedican a las labores del hogar, aunque un porcentaje importante de las mismas, el $29 \%$ están vinculadas laboralmente. Su nivel educativo es primaria y secundaria para el $34.5 \%$ y $42.7 \%$ de los registros; el agresor alcanzó niveles de educación primaria en el $35.8 \%$ de las notificaciones y secundaria en el $45.2 \%{ }^{21}$. El comportamiento desagregado de la violencia intrafamiliar por años para los principales tipos de violencia en Manizales se registra en la gráfica.

Con relación al incremento de la participación de la mujer por encima del 30\%, en las instancias de toma de decisiones políticas se plantea para el ODM 3. Fue evidente su baja representatividad política para el periodo 2008 -2011; muy baja tanto su candidatización para ocupar alguna de las curules disponibles, como el apoyo por parte de la ciudadanía al momento de hacer la elección. Como relevante aparece la postulación de la mujer a las J untas Administradoras Locales con una participación fue del $40.7 \%$ y un total de 228 mujeres inscritas.

Muy reducida la participación femenina en los Concejos Municipales, sin alcanzar ninguna curul en Aguadas, Anserma, Marmato, Marulanda, San José y Victoria, con mayor participación, 4 cúreles en total en Manizales y la Dorada. I gual situación, se registra a nivel de Alcaldías, con solo Chinchiná y Pácora con representación femenina en las alcaldías; igual situación se registra para el caso de la Asamblea departamental constituida por 11 hombres y 3 mujeres de las 19 aspirantes; no se inscribe para el periodo 2008 - 2011 ninguna candidata a la gobernación departamental. No existe para el departamento, representación de la mujer en la Cámara de Representantes y a

20 Ibidem.

21 Tendencia de la Violencia Intrafamiliar en Manizales. 2003-2006. Sistema de Vigilancia Epidemiológica del Violencia Intrafamiliar. Alcaldía de Manizales. Centro de Atención a la Violencia Intrafamiliar.

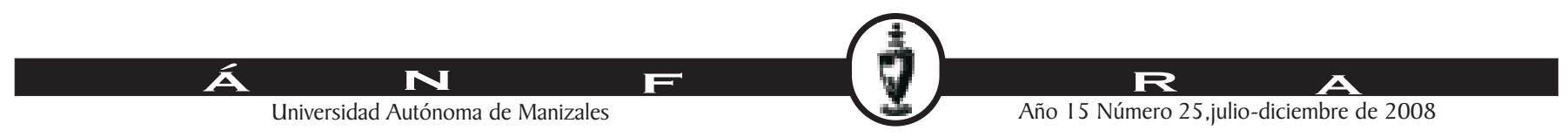


nivel de Senado se cuenta con la participación de una mujer entre los cuatro senadores de Caldas.

Otra de las dimensiones abordadas desde la equidad de género, fue el tipo de empleo y el rango salarial de la mujer vinculada a cargos de la administración pública tanto en la Alcaldía de Manizales ${ }^{22}$ como en la Gobernación para periodo 2004 - 2007. En la Alcaldía de Manizales, de 514 empleos, la mujer participa del $44.94 \%$ de los cargos, ocupa sólo el $18.75 \%$ en los niveles directivos con tres posiciones y su presencia es mucho mayor en los niveles profesional, técnico y asistencial.

Gráfica No 9. Cargos por Género en el sector público. 2004- 2007.

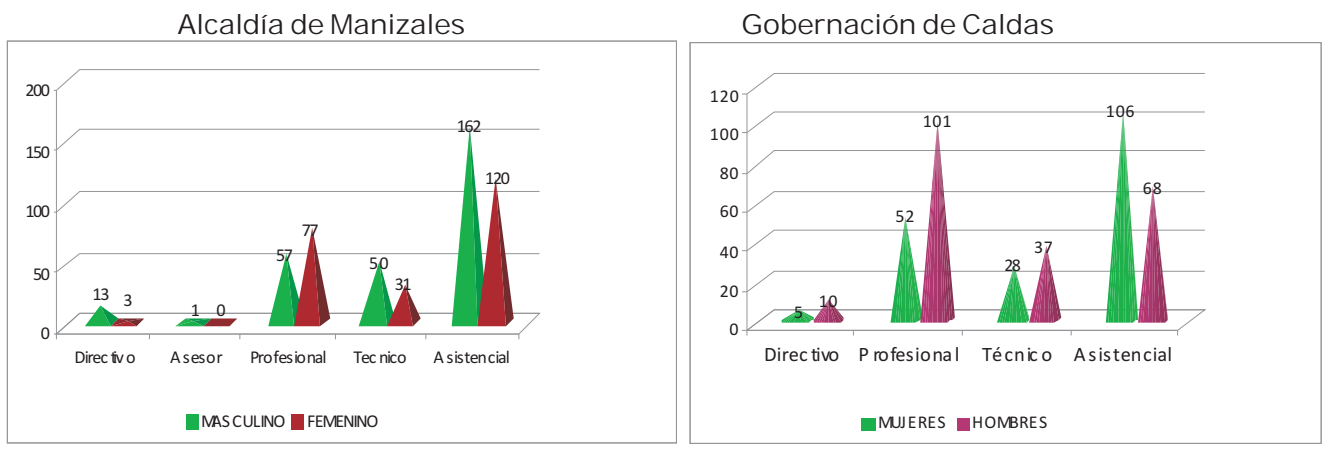

Fuente. Información suministrada por la Alcaldía de Manizales y la Gobernación de Caldas. 2007

Al evaluar nivel académico por género para la alcaldía, se encontró un mayor logro por parte de la mujer, superando en mayor proporción los niveles de primaria y secundaria, donde el $50.43 \%$ tienen pregrado. La escala salarial va entre $\$ 6.044 .155$ a nivel directivo y \$616.051 para el asistencial. La mayor concentración de los cargos está en el nivel profesional con salarios entre $\$ 1.447 .871$ y \$3.620.989. Los salarios dependen de la responsabilidad del cargo y no del género de los empleados ${ }^{23}$. En la Gobernación, la mujer ocupa el $47.10 \%$ de los 414 cargos con una representación del $33.33 \%$ en el nivel directivo, $33.98 \%$ en el profesional, $43.07 \%$ en el técnico y $60.91 \%$ en el asistencial. La escala salarial va entre \$7.460.194 y \$634.811, con 48 cargos en el nivel de Profesional Universitario con salario mes de $\$ 1.559 .667 ; 41$ Auxiliares Administrativos 1 con \$646.089; 37 Profesionales Especializados 3 con \$2.440.779; y 37 Auxiliares de Servicios Generales con \$ 461.255. Al igual que en la alcaldía de Manizales, los salarios se asignan según perfil del cargo independientemente del sexo del empleado. Por resaltar en la Gobernación, la estabilidad laboral de sus empleados donde sólo el $2.9 \%$ tiene menos de un año de vinculación; el $53.75 \%$ registro una permanencia mayor a los 6 años ${ }^{24}$.

Desde lo local, el análisis del mercado, muestra que el $44 \%$ de las mujeres, en 2000 , estuvieron ocupadas en algún oficio remunerado, tasa sensiblemente inferior a la masculina ${ }^{25}$. Así mismo, la relación entre las mujeres vinculadas laboralmente y aquellas en edad de trabajar es de $42 \%$, es decir que 4 de cada 10 . Para el mismo periodo, la tasa de ocupación femenina fue del $32.24 \%$, frente al $67.95 \%$ para el sexo masculino en el mismo periodo. La situación descrita presenta un comportamiento similar a nivel nacional con tasas de $38.49 \%$ y $66.71 \%$ para mujeres y hombres respectivamente $e^{26}$.
22 Alcaldía de Manizales. 2007.

23 Ibidem.

24 Información suministrada por la Gobernación de Caldas. Octubre 2007.

25 ECH. Web DANE.

26 Ibidem.

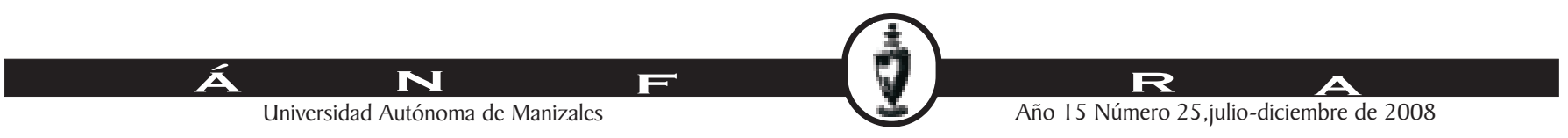


ODM 4. Reducir la mortalidad infantil.

La población infantil es la más frágil y vulnerable frente a los problemas socioeconómicos y ambientales del entorno, por esta razón ha sido priorizada en las metas de desarrollo a alcanzar para el 2015. La línea base para el ODM 4, se realiza fundamentalmente, a partir de la información suministrada por la Dirección Territorial de Salud con base en los perfiles epidemiológicos elaborados en cada municipio. Según la información suministrada, en el 2006 se registran 183 muertes de menores de 1 año y 93 para el primer semestre de 2007. Las causas de mortalidad fueron similares en los dos periodos. Las 10 primeras causas de mortalidad y el número de eventos se registran en la tabla.

\begin{tabular}{|l|c|c|}
\hline \multicolumn{1}{|c|}{ Causa de mortalidad } & $\mathbf{2 0 0 6}$ & $\mathbf{2 0 0 7}$ \\
\hline $\begin{array}{l}\text { 1. Trastornos respiratorios específicos del período } \\
\text { perinatal }\end{array}$ & 52 & 24 \\
\hline 2. Malformaciones y anomalías congénitas & 29 & 21 \\
\hline 3. Malformaciones del sistema circulatorio & 23 & 18 \\
\hline 4. Retardo del crecimiento fetal y bajo peso al nacer & 19 & 16 \\
\hline 5. Afecciones propias del periodo perinatal & 12 & 7 \\
\hline 6. Infecciones propias del periodo perinatal & 11 & 6 \\
\hline 7. Neumonía & 9 & 9 \\
\hline 8. Trastornos Hemorrágicos y hematológicos & 6 & 6 \\
\hline 9. Accidentes que obstruyen la respiración & 6 & 6 \\
\hline $\begin{array}{l}\text { 10. Meningitis y otras inflamaciones del sistema } \\
\text { nervioso. }\end{array}$ & 5 & \\
\hline
\end{tabular}

Fuente: Dirección Territorial de Salud de Caldas. Perfil Epidemológico de Caldas. 2007

Catorce de los 27 municipios de Caldas han alcanzado la meta de 14 o menos casos de niños menores de 1 año muertos por 1.000 nacidos vivos. Los municipios que aún no cumplen la meta, con las mayores tasas de mortalidad infantil son Marulanda (64.52) y Pácora (36.46). Para menores de cinco años, este indicador es decreciente, pasando de 20.5 a 17.1 por mil NV en el periodo 2002- 2006. Para el último año se presentaron 222 muertes de niños y niñas. Por municipios, 15 han alcanzado la meta de 17 niños muertos por cada 1.000 nacidos vivos y 12 aún no la alcanzan. La situación es crítica para Marulanda con 64.5, Marmato con 40.3 y Pácora con 36.5. (Gráfico 10)

El mayor número de muertes se registró en Manizales ( 77 casos), seguida de La Dorada ( 24 casos), Chinchiná ( 16 casos) y Riosucio con 12 (casos). Las 10 primeras causas de muerte fueron ${ }^{27}$ la neumonía y el ahogamiento accidental ( 3 casos $\mathrm{c} / \mathrm{u}$ ), seguido de malformaciones y anomalías congénitas entre otras con muy bajas frecuencias. La Enfermedad Diarreica Aguda (EDA) y la Infección Respiratoria Aguda (IRA) continúan siendo un problema de salud pública, a pesar de su notable reducción. EI IRA afecta tanto en morbilidad como en mortalidad en menores de cinco años, especialmente en los municipios más deprimidos. Entre 2002 y 2006 se redujo de 11 a 2 casos. La IRA, no solo constituye la primera causa de consulta médica, sino que causa más muertes que la EDA. Su reducción no es tan significativa al pasar de 10 casos en 2002 a 9 en 2006.
27 Dirección Territorial de salud de Caldas. Perfil epidemiológico de Caldas. I semestre de 2007. Estadísticas Vitales. En proceso de edición.

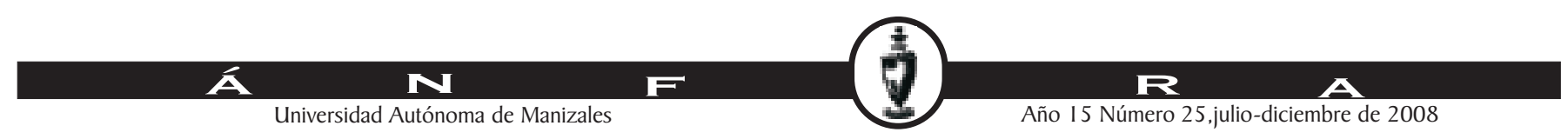


Gráfica No10. Tasas de Mortalidad Infantil en menores de 1 y 5 años por 1000 nacidos vivos. Caldas. 2007

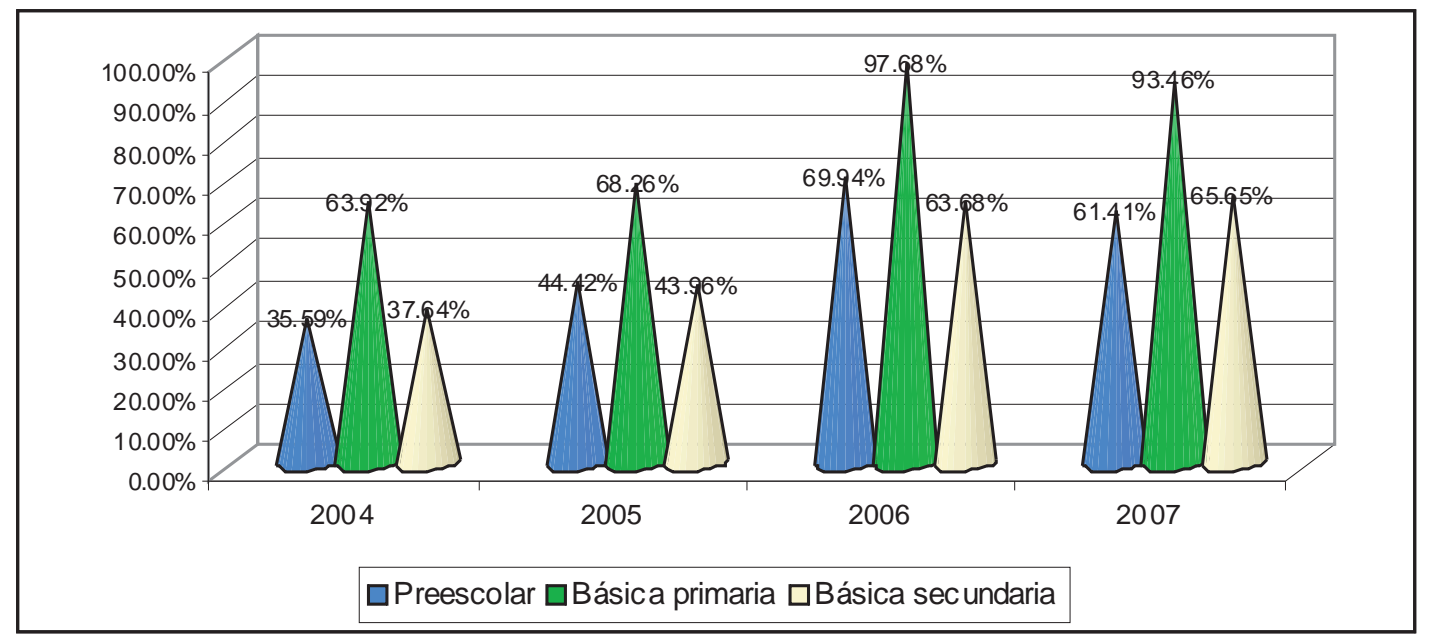

Fuente. Secretaria de Educación del Departamento. 2007. Línea Base ODM. Caldas. UAM- CEA. 2008.

La cobertura en vacunación por tipo de vacuna en menores de un año con dosis completas disminuyó con relación al 2004. Para el 2006 la aplicación de la BCG alcanzó una cobertura del $64.5 \%$, y para el resto se reportan coberturas inferiores al $70 \%$ exceptuando la triple viral con cubrimiento del $74.7 \%{ }^{28}$. Según la Dirección Territorial de Salud de Caldas, las metas de vacunación para menores de 5 años no han sido alcanzadas por Aguadas, Anserma, Filadelfia, La Merced, Marulanda, Pácora, Palestina, Pensilvania y Samaná.

\section{ODM 5: Mejorar la salud sexual y reproductiva.}

La salud sexual y reproductiva en el Departamento, prioridad del PAB, se apoya en la Ordenanza 552 de 2006 "Política de Salud Sexual y Reproductiva" y en la formulación del Plan de Salud Pública de Caldas 2007 (en edición) y la línea base para el ODM 5 en Caldas, se documenta a partir del análisis de las seis metas definidas para su logro.

- Reducción de la tasa de mortalidad materna a 45 muertes por cien mil nacidos vivos. Los eventos de mortalidad materna se registran en 5 municipios, con un total de 9 casos para el 2006, distribuidos así: 4 en Manizales, 2 en Manzanares y 1 en Villamaría, Aguadas y La Dorada respectivamente con una tasa para Caldas del $68.58 \%$. Considerando la mortalidad materna como uno de los principales indicadores de salud pública, es importante tener en cuenta que el porcentaje de mujeres en edad fértil afiliadas al SGSSS ${ }^{29}$ no corresponde al $100 \%$ de éstas, con coberturas de afiliación inferiores al 50\% en La Dorada, Belalcazar, La Merced, Norcasia, Pácora y Villamaría ${ }^{30}$.

- Incrementar a $\mathbf{9 0 \%}$ el porcentaje de mujeres con cuatro o más controles prenatales. Llama la atención 10 municipios con un porcentaje menor al $90 \%$ de mujeres embarazadas con un número de controles de gestación no mayor a 4, como el caso de Marulanda $(61,1 \%)$ y Pensilvania (68\%).

\footnotetext{
28 Subdirección de Salud Pública, Grupo PAI. En: Cómo va la Salud en Caldas. DTSC. Población Ministerio de Protección Social. 2007.

29 SGSSS: Sistema General de Seguridad Social en Salud

30 Perfil epidemiológico de Caldas. I semestre de 2007. Indicadores de niñez y adolescencia. capítulo XIII por municipio. En proceso de edición.
}

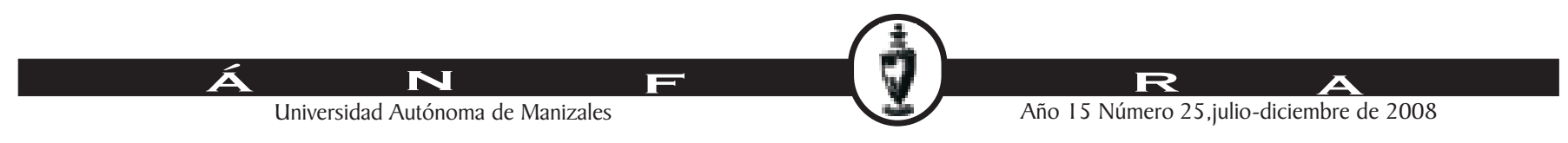


- Incrementar la atención institucional del parto y por personal calificado en un $\mathbf{9 5 \%}$. Caldas cumple con la meta fijada del $95 \%$, al presentar en promedio un $96 \%$ de mujeres con atención del parto a nivel institucional; sin embargo, Marulanda se encuentra por debajo de la meta con un registro solo del $85 \%$; el resto de los municipios en Caldas que aún no logran la meta están entre el 90-94\%. En un porcentaje del $100 \%$ están Filadelfia, Palestina, Risaralda, Salamina y San J osé.

- Incrementar la prevalencia del uso de métodos modernos de anticoncepción en la población sexualmente activa a $75 \%$ y a $65 \%$ entre la población de 15 a 19 años y en la población general respectivamente. El promedio para Caldas es de $63.2 \%$. Preocupante resultan los hallazgos obtenidos en un estudio realizado por la Dirección Territorial de Salud en 2006 con 645 hombres y 710 mujeres de 16.9 años de edad en promedio pertenecientes a 26 municipios. El estudio reporto que menos del $40 \%$ de los jóvenes usan condón y otros métodos anticonceptivos ${ }^{31}$. La situación requiere de la disponibilidad de alternativas para posicionar el uso de los métodos anticonceptivos entre los jóvenes, dado que aún persisten elementos culturales que dificultan que la educación trascienda de los tradicionales procesos de transmisión de información para consolidarse en verdaderos procesos de formación y empoderamiento de la población juvenil con respecto a la educación sexual positiva ${ }^{32}$.

- Detener el crecimiento del porcentaje de adolescentes que han sido madres o están en embarazo, manteniendo esa cifra por debajo del $\mathbf{1 5 \%} \%$. Preocupante para el departamento que ningún municipio haya alcanzado la meta, registrándose un promedio para Caldas de $26.5 \%$. Los más altos porcentajes de embarazos en adolescentes se registran en Palestina y Victoria.

Gráfica No11. Porcentaje de embarazo en adolescentes. Caldas. 2006

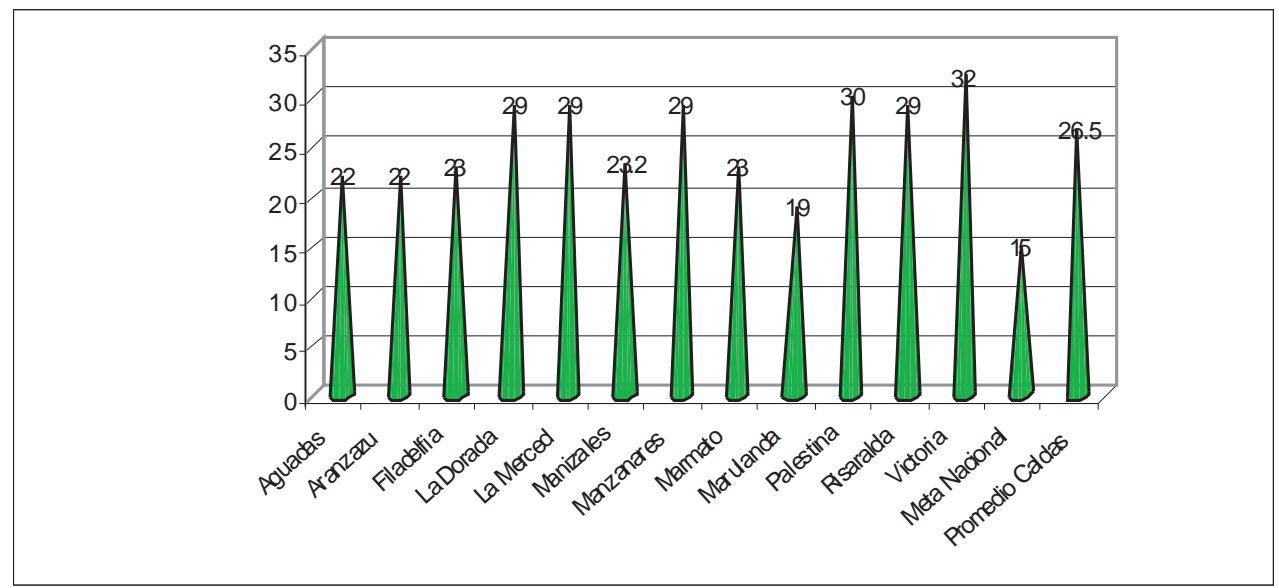

Fuente: Dirección Territorial de salud de Caldas. Perfil epidemiológico de Caldas. I semestre de 2007. En proceso de edición

Embarazos en niñas de 10 a 14 años son identificados en Supia, La Dorada, Aguadas, Anserma, Aranzazu, Chinchiná, Manzanares, Manizales, Pácora, Palestina, Pensilvania, Riosucio y Salamina ${ }^{33}$. Este registro asociado a que la obertura de salud sexual y reproductiva en algunos municipios como Aguadas, Anserma, Filadelfia, Neira,
31 Fuente; Dirección Territorial de Salud en Caldas. Cómo va la salud en Caldas. Edición especial.2006. Pág. 6, 14.

32 En el estudio de la Dirección Territorial de Salud se encontró también que el $67 \%$ de los hombres habían experimentado su primera relación sexual a los 14,1 años y las mujeres en un $46,8 \%$ a los 15,5 años. Se resalta en la investigación.

33 Fuente: Perfil epidemiológico de Caldas. I semestre de 2007. Indicadores de niñez y adolescencia. capítulo XIII por municipio. En proceso de edición.

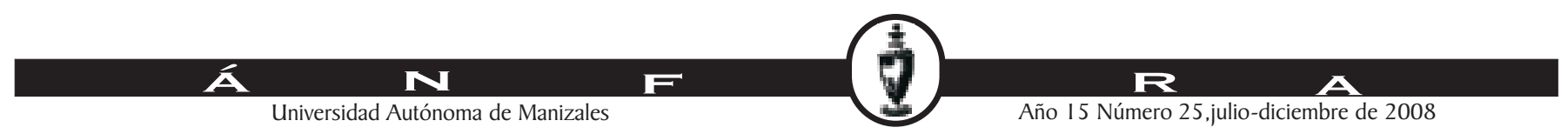


Pensilvania, Risaralda, Salamina y Viterbo es menor al 50\% incrementa el problema y aleja a Caldas de la meta propuesta con un registro para 2006 de $26.5 \%$ de adolescentes en estado de embarazo.

- Reducir la tasa de mortalidad por cáncer de cuello uterino a $\mathbf{5 . 5}$ por cien mil mujeres. Caldas se ubica por encima de la meta ODM; nueve de cada 100.000 mujeres mueren a causa de cáncer de cuello uterino. Sin embargo, en términos desagregados, existen municipios bastante problemáticos con tasas superiores a $30 \%$ : Aranzazu ( 2 casos de 6186 mujeres), La Merced ( 1 caso de 3102 mujeres), Norcasia ( 1 caso de 3175 mujeres) y Samana ( 4 casos de 8871 mujeres).

ODM 6: Combatir el VIH/SIDA, la malaria y el dengue.

El programa de control de transmisión vertical para VIH/SIDA ha arrojado buenos resultados en las gestantes no aseguradas; en los últimos años se han realizado 8.950 pruebas de ELISA en este grupo poblacional. En el régimen contributivo y subsidiado el programa ha sido irregular y de pobre compromiso, en el 2005 se presentaron dos casos posiblemente prevenibles.

Para la Prevalencia de la infección de sida por 100.000 habitantes, como se aprecia en la gráfica, la volatilidad del indicador refleja un sistema de información con bajo grado de confiabilidad, dado los quiebres abruptos de la tendencia. El sistema reporta solo los casos de pruebas voluntarias, lo cual, se traduce tanto a nivel nacional como departamental, en un desconocimiento de la verdadera prevalencia. Filadelfia presentó la mayor incidencia de Sida en el 2005, seguido por Chinchiná, Manizales, Villamaría y Aranzazu.

Gráfica No12. Prevalencia de VIH/Sida en población general por 100.000 habitantes.

Caldas. 2001 - 2006

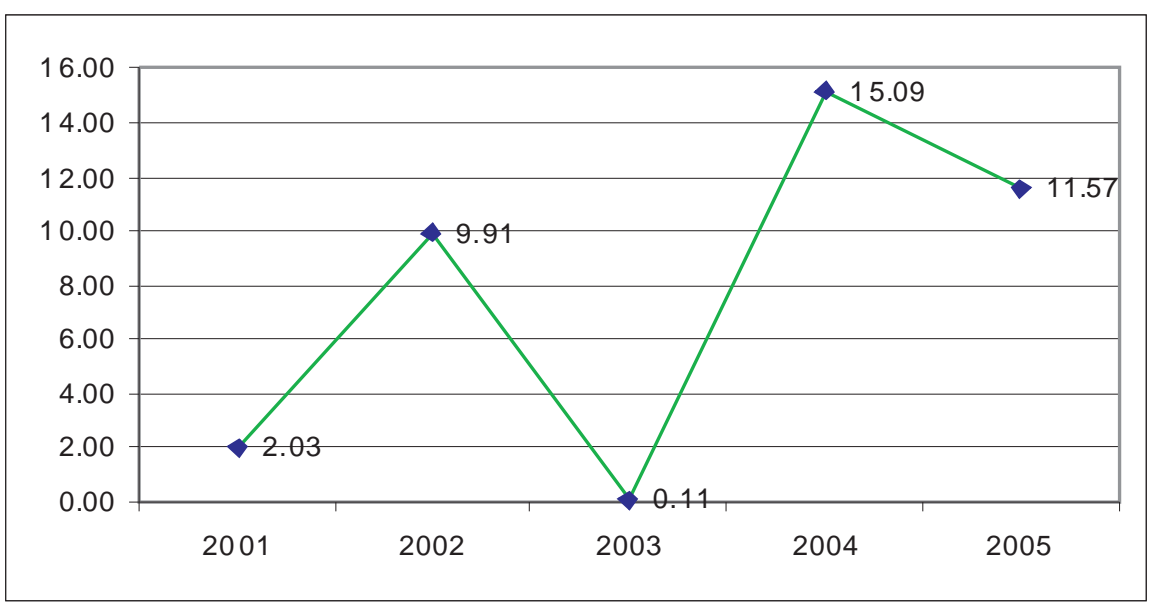

Fuente: PNUD a partir de datos SIVIGI LA cálculos del PNDH

En cuanto a morbilidad, por problemas de salud asociados al SIDA, están en orden de importancia Risaralda, Manizales y Chinchiná. Para el 2002 la mortalidad por SIDA en Caldas fue de 0.11 , de 14.02 para 2003 y de 0.22 para 2005.

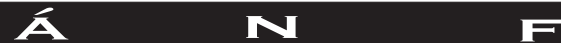

Universidad Autónoma de Manizales 
Frente a la malaria, ésta se encuentra por debajo del nivel nacional y no es considerada por la administración pública como prioritaria, al contrario de la Leishmaniasis con 315 casos en 2004, 317 en 2005 y 229 en 2006.

Para dengue, aunque el número de casos no es representativo, se encuentran afectados principalmente Chinchiná, La Dorada, Palestina y Viterbo; el comportamiento de los índices aédicos ha sido bastante favorable en Caldas, donde desde el 2003 no se presentan brotes importantes de Dengue y Fiebre Amarilla.

Con base en las recomendaciones de los actores se debe incluir la Tuberculosis, la Lepra y otras enfermedades de transmisión sexual como la Hepatitis B y Sífilis Congénita, al igual que la atención a discapacitados dentro de las prioridades para Caldas.

\section{ODM 7. Garantizar la Sostenibilidad del Medio Ambiente.}

El análisis se realiza a partir de la identificación de componentes claves identificados con diversos actores de la sociedad, los cuales deben ser abordados en forma articulada y racional en el intento de avanzar hacia un desarrollo sostenible.

- Parques Naturales. El Parque Nacional Natural Los Nevados, con 58.300 hectáreas hace parte de Caldas, Risaralda, Quindío y Tólima. Caldas, tiene el 13\% (7.500 hectáreas), ubicadas exclusivamente en Villamaría. El parque cubre uno de los mosaicos naturales más complejos de Colombia, con las máximas elevaciones de la cordillera Central y parte de la unidad volcánica activa de los Andes, su punto más alto esta a 5300 m.s.n.m. en las nieves perpetuas del nevado del Ruiz y desciende hasta los 2.400 en su cuota más baja.

- Planes de manejo ambiental. Dada la importancia del Departamento como fuente abastecedora de agua para consumo humano, agrícola e industrial, el Plan de Manejo Ambiental del parque, así como los Planes de Manejo de las zonas amortiguadoras de las Corporaciones Autónomas Regionales (CAR), centran su atención en el diagnóstico, planificación y ejecución de programas y proyectos tendientes a la conservación y protección del recurso hídrico. Adicionalmente, el Parque Nacional Natural Los Nevados, cuenta con formulación de Plan de Manejo 2006-2010, aprobado por la resolución 052 del 26 enero de 2007 de la Unidad Administrativa Especial del Sistema de Parques Nacionales Naturales. El Plan de manejo del Parque de la Selva de Florencia está en proceso; la selva tiene un total de 10.000 hectáreas, 6.000 de éstas cedidas a la Unidad Administrativa de Parques Nacionales.

- Reforestación de Bosques Naturales. El promedio de reforestación actual para Caldas es 273 hectáreas/año $0^{34}$. No obstante, se propone utilizar el indicador de pérdida de área boscosa y pérdida de biodiversidad, como una forma paralela de mirar el manejo de los bosques naturales valorado como un importante indicador para la definición de políticas en planeación y gestión ambiental.

- Protección de la Capa de Ozono. El consumo promedio de sustancias agotadoras de la capa de ozono (SAO) para Caldas es de 5.65 toneladas, el cual se considera bajo comparado con el nacional ${ }^{35}$. El mayor consumo para la zona cafetera se da en Pereira por tener un mayor desarrollo del sector refrigeración y aire acondicionado. Se considera que Manizales tiene un bajo consumo, aunque existe una industria de refrigeración (MABE) y un número considerable de técnicos en el servicio, muchos de ellos de formación empírica, convirtiéndose en factor de riesgo.

\footnotetext{
34 PAT $2007-2009$

Corpocaldas.

35 Corpocaldas, 2006.
}

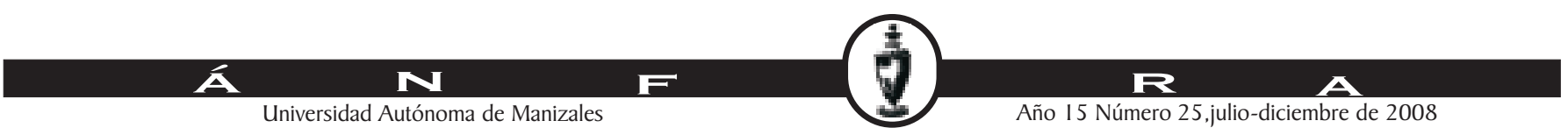


- Acueducto y Alcantarillado Urbano y Rural ${ }^{36}$. En la prestación de servicios públicos de acueducto y alcantarillado, Caldas se encuentra por encima de los promedios nacionales tanto en lo urbana como rural, con $98,7 \%$ y $60,3 \%$ respectivamente. No obstante, por subregiones se presenta altas disparidades en la prestación de estos servicios, especialmente para la región oriente. Vale la pena resaltar la situación crítica para Norcasia, Pensilvania, Marquetalia y Samaná.

Gráfica No13. Cobertura Acueducto Rural y Urbano. Caldas. 2005

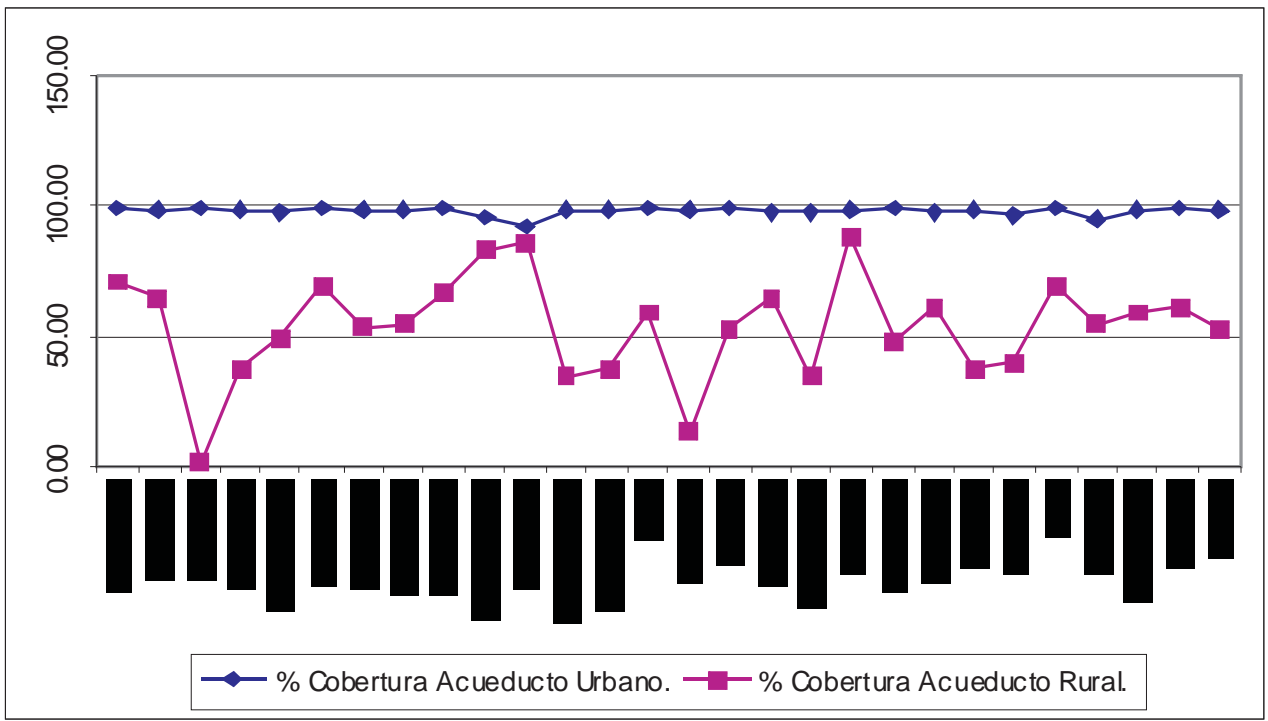

Fuente: DNP, DANE, Gobernación de Caldas, 2005. Línea Base ODM Caldas. CEA-UAM. 2008.

Gráfica No14.Cobertura Alcantarillado Rural y Urbano. Caldas. 2005.

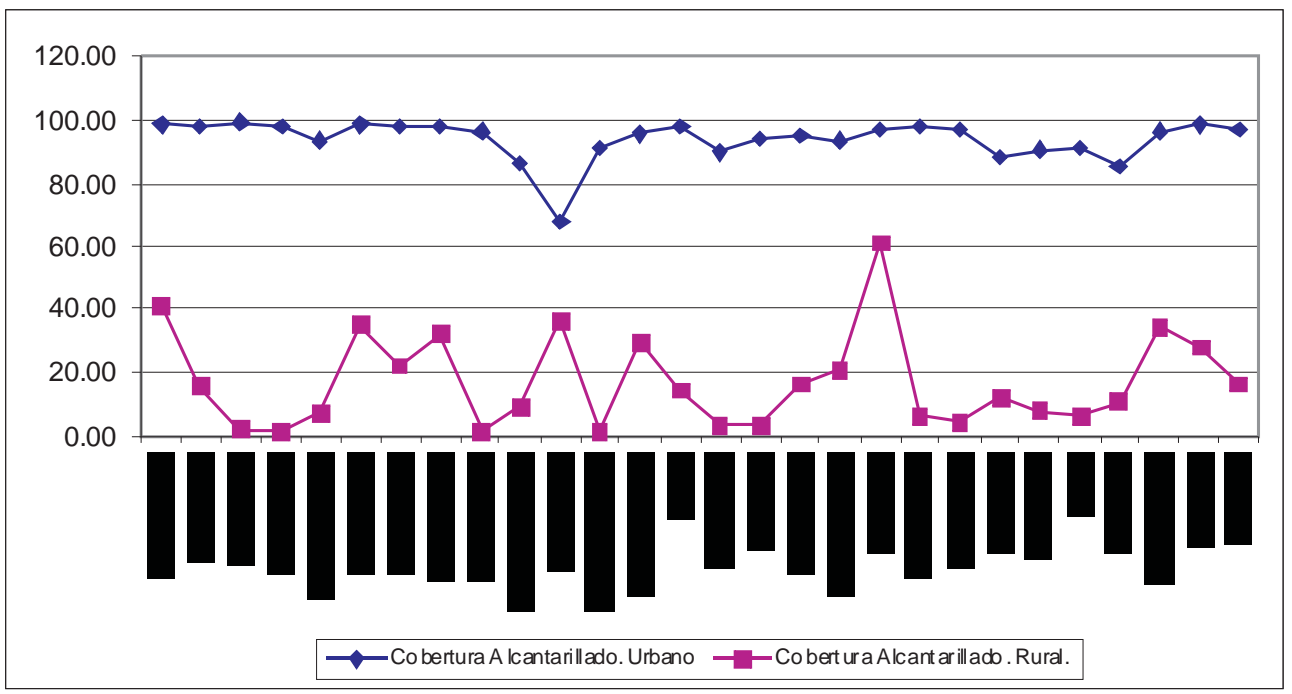

Fuente: DNP, DANE, Gobernación de Caldas, 2005. Línea Base ODM Caldas. CEA - UAM. 2008
36 DNP, DANE, Gobernación de Caldas, 2005

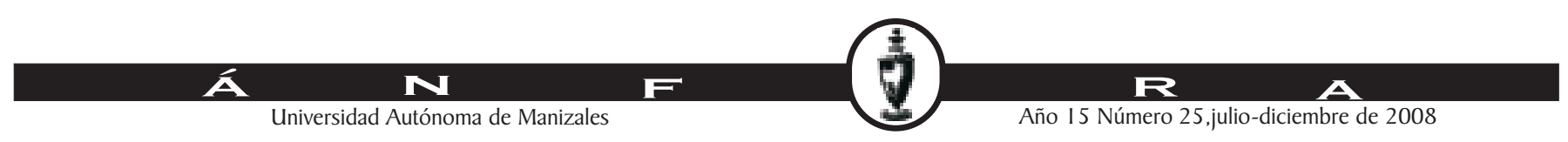


Calidad del Agua. Con base en los análisis físico- químicos y bacteriológicos realizados en el 2006 y el primer semestre de 2007 por la Dirección Territorial de Salud de Caldas, municipios como Marmato y Norcasia no disponen de agua apta para el consumo por presentar E-coli y coliformes totales. La Merced también registra agua en condiciones no aptas pare el consumo, siendo la situación más problemática a nivel rural.

- Destugurización. Caldas presenta 3.7\% de viviendas en riesgo, ubicándose por debajo de la meta nacional definida en el $4 \%$. Dentro de esta categoría se consideran el hacinamiento y las construcciones con materiales inadecuados y sin servicios de saneamiento. Los municipios que reportan mayor porcentaje de viviendas en riesgo son Manizales 10.7\%, Samana 9.5\% y La Dorada (23.2\%) con una situación, donde es particularmente crítica la situación dado que un cuarto de su población se halla en riesgo por inundación.

- Manejo de residuos sólidos. El manejo de los residuos sólidos, como un factor de contaminación, ha sido atendido, entre otras, a partir de una adecuada recolección de las basuras, con el mejor desempeño en La Dorada, Riosucio, Manizales y Chinchiná y con menor cobertura Manzanares, La Merced, San J osé y Samaná.

- Contaminación de ríos. Todos los municipios reportan problemas de contaminación en sus ríos y quebradas, a nivel urbano y rural. Corpocaldas en el Trienio 2004-2006 instalo 3.499 sistemas de tratamiento de aguas residuales domésticas. Frente a la contaminación por aguas industriales, la ley exige remover el $80 \%$ de la carga orgánica antes de ser vertidas en los efluentes; esta condición se cumple en Manizales, aunque debe ser mayor el porcentaje exigido de carga orgánica a remover. Por el $20 \%$ restante de carga vertida, las industrias pagan tasas retributivas.

- Exposición a plaguicidas. En Caldas la exposición a plaguicidas es un problema de salud pública, debido al incremento de la demanda en el uso de los mismos y al impacto en la salud de la población y en el ambiente especialmente en las zonas rurales. En 2006 se presentaron 246 casos de intoxicaciones, con un claro aumento con relación al 2005 con 145 casos reportados.

\section{ODM 8. Fomentar una Sociedad Mundial para el Desarrollo.}

Importante desatacar en términos de transparencia y confianza en lo público, que el gobierno departamental registra una mayor inversión pública frente a los gastos de funcionamiento, cumpliendo con lo establecido en la Ley 617 de 2000 para el periodo 2004 - 2007. Así mismo, el perfil de la deuda presentó un buen comportamiento según lo establecido en la Ley 358 de 1997 con los indicadores de solvencia y sostenibilidad en un nivel inferior al exigido por la norma (solvencia $5 \%$ del $40 \%$; sostenibilidad $23 \%$ del $80 \%)^{37}$

El comportamiento de los ingresos tributarios del departamento durante los últimos años ha presentado una tendencia favorable, con un incremento de $15 \%$ en el 2006 comparado con el 2005 y con un promedio de $12 \%$ para los últimos cinco años. El desempeño fiscal y financiero le permitió al departamento en el mes de octubre del 2007 tener una calificación "A+" A más, por parte del Comité Técnico de Calificación de Duff \& Phelps de Colombia S.A. Sociedad Calificadora de Valores ${ }^{38}$. En términos generales, en Caldas se dio cumplimiento en más del 100\% al plan de inversiones aprobado en el plan de desarrollo "Caldas 100 años con los Objetivos del Milenio".
37 Gobernación de Caldas. Secretaria de Hacienda. 2007.

38 Concepto enviado por Duff \&Phelp al Gobernador de Caldas en comunicación de Octubre 17 de 2007 .

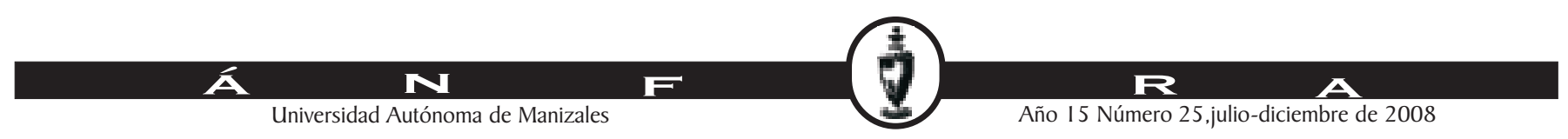


Como limitante para el desarrollo, existe en Caldas, una gran dependencia del Sistema General de Participaciones (SGP), especialmente para municipios como Aguadas, La Merced, Filadelfia, Salamina, Samana. Asociado a este fenómeno, se presenta un alto porcentaje de los ingresos corrientes de los municipios destinados a funcionamiento. Esta situación es más crítica en Neira, Chinchiná, Salamina, Samana, Aguadas, Belalcázar y Marmato, con una disminución notable en los recursos municipales requeridos para inversión en áreas estratégicas del desarrollo humano sostenible como salud, educación, cultura, saneamiento básico, entre otras.

Frente al promedio de gasto municipal dedicado a la inversión en los municipios de Caldas es $77.77 \%$, con Risaralda y Chinchiná en los extremos superior e inferior respectivamente con valores del $98.76 \%$ y $49.61 \%$. Villamaría reporta los mejores indicadores para capacidad de ahorro, seguido de La Dorada, Victoria y Norcasia; con la más baja capacidad de ahorro aparecen Marmato con una tasa negativa del $-0.33 \%$, Chinchiná con el 3.16\% y Neira con 3.59\%, donde además estos dos últimos aparecen destinado a gastos de funcionamiento el $100.06 \%$ y $94.10 \%$ de sus ingresos corrientes ${ }^{39}$.

Según el indicador del desempeño fiscal para los municipios de acuerdo a los límites establecidos en la Ley 617 de 2000, que establece el $60 \%$ de los ingresos corrientes como límite máximo para ser invertidos en gastos de funcionamiento, se destaca Villamaría con el peor desempeño fiscal ${ }^{40}, 64.45 \%$ de su ingresos dedicados a funcionamiento y Salamina con los mejores indicadores con solo el $36.16 \%$ de sus ingresos con esta destinación.

Es importante destacar, que tanto la gestión municipal, como del departamento, a favor de las Metas de Milenio, se han visto fortalecidas por el esfuerzo articulado entre actores, resaltando el trabajo de las ONG's pertenecientes a la Federación de ONG's de Caldas. El 54\% de sus acciones se dirigen a contribuir con la erradicación de la pobreza extrema y el hambre y en menor proporción a reducir la mortalidad infantil. Se destaca su gestión financiera a favor del desarrollo. Para 2006 muestran una ejecución de $\$ 63.138$ millones, de los cuales el $59 \%$ correspondieron a recursos públicos, $14 \%$ a privados, $13 \%$ a propios, $11 \%$ a cooperación internacional y un $3 \%$ a otras fuentes ${ }^{41}$.

Cultivos Ilícitos. La siembra de cultivos ilícitos, según UNODC-SIMSI (2006), se concentra en el Oriente, con mayor proporción en los municipios de Samana y Norcasia con 132 y 46 hectáreas respectivamente, registrando además el mayor número de hectáreas erradicadas en forma manual (282.21 y 208.87 respectivamente). En las últimas décadas se ha incrementado el desplazamiento de la población debido a la violencia, el conflicto armado, el tráfico de drogas y, en general, la búsqueda de mejores condiciones de vida. Según la Red de Solidaridad Social (RSS), el número total de desplazados es de 54.291 personas, registrando como principales expulsores a Samaná (30.095), Pensilvania (8.527), Riosucio (2.703), Marquetalia (1.693), Manizales (1.389) y Anserma (1.308) ${ }^{42}$.

\section{Retos de caldas frente a los ODM.}

Fundamental para Caldas, el fortalecimiento de una alianza para el desarrollo en aras de avanzar en el logro de las metas. Trabajo en red, cooperación, conectividad, solidaridad, transparencia, buen gobierno, reconocimiento, participación ciudadana, entre otros, son parte de los atributos que debe tener esa gran iniciativa por la justicia y
39 Anexo Estadístico Municipalizado. Información 2006. Información suministrada por PNUD. 2007.

40 Sin embargo, Villamaría reporta los mejores indicadores para capacidad de ahorro, seguido de la Dorada, Victoria y Norcasia.

41 Federación de ONG's de Caldas. Rendición social de cuentas 2006.

42 SIPOD. Fecha de Corte: 3 de septiembre de 2007.

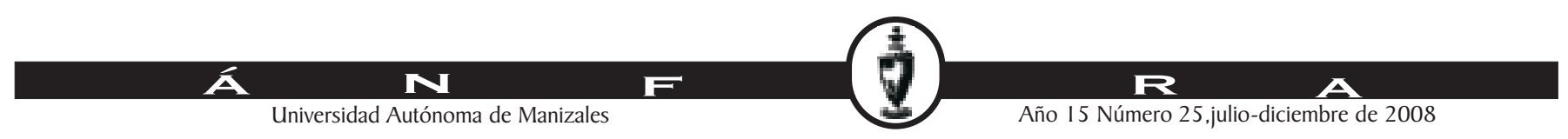


la equidad, en complementariedad y continuidad con las políticas públicas en los diferentes niveles territoriales.

Se identifica como una gran limitante a la hora de planificar el desarrollo la ausencia de información oportuna, veraz y unificada requerida al momento de tomar decisiones. Es manifiesta una gran preocupación frente al rol del DANE, y el suministro de información relacionada con datos de población, entre otras, dado el impacto generado a nivel presupuestal, particularmente en el tema de las transferencias de la Nación. El hecho de que la información del Censo 2005 no esté disponible a nivel municipal y la falta de agilidad en el suministro de la misma a nivel departamental, requiere la urgencia de descentralizar y dinamizar estas oficinas como centros operativos y de coordinación de los diferentes Sistemas de I nformación que se precisan desde los niveles locales.

\section{Algunas estrategias concretas propuestas para la acción son las siguientes.}

- Información, comunicación y promoción de los ODM: fundamental realizar una tarea masiva de difusión y educación frente a los ODM para poder generar el compromiso frente a sus metas. Esta acción debe ser liderada desde los diferentes sectores de la sociedad. Se propone la realización de talleres y foros municipales itinerantes con niños y jóvenes, y adultos y socializar los resultados y las metodologías empleadas en los diferentes trabajos realizados en Caldas en torno al tema del desarrollo. Se mencionan: Talleres del Milenio, Plan decenal de Educación, Pacto por el desarrollo humano, Agenda de Competitividad, Informes Regionales de Desarrollo Humano, los resultados de los Talleres del Milenio de Jorge Garay y el Pacto por el Desarrollo Humano.

- La Planificación territorial participativa: se considera la herramienta para avanzar en el logro de los ODM. Se debe lograr la articulación de propósitos y programas entre los diferentes niveles territoriales de planificación: nacional, departamental y municipal, así como la promoción de la participación ciudadana y comunitaria, particularmente de los jóvenes y de las mujeres, para lograr consensos entorno a los obj etivos y al diseño de mejores estrategias para lograrlos.

- Los Distritos Agroindustriales como las unidades territoriales pertinentes para apalancar el desarrollo económico local: sin crecimiento económico no se puede alcanzar el desarrollo de la población, por lo tanto se requiere de un tejido económico fuerte, diversificado y coherente con las potencialidades físicas y culturales de la población. Los distritos agroindustriales deben transitar hacia Agencias de Desarrollo Local desde los cuales a partir de la convergencia entre actores, se creen los entornos propicios para el desarrollo. El sector agropecuario debe industrializarse, agregar valor, así como especializarse por regiones de acuerdo con sus potencialidades con políticas dirigidas a incrementar la producción y la productividad del sector: investigación, extensión, servicios, crédito, mercadeo e infraestructura básica.

- Inversión en Capital Humano municipal: Se considera esencial la promoción de una Educación de calidad y con pertinencia a nivel municipal, con mayor cobertura a nivel Medio, Técnico y Universitario. Se requiere un sistema educativo que forme sujetos contextualizados que aporten soluciones a los problemas de su entorno. El acceso de los jóvenes de las regiones lejanas a las Universidades de Manizales se propone a través de varias estrategias: ICFES ponderados, subsidios y becas, facilitación de vivienda, alimentación y

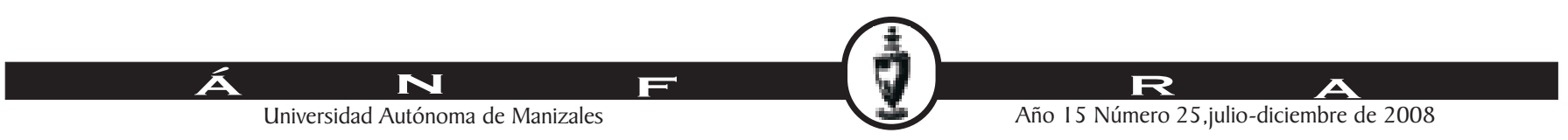


transporte, así como la oferta de programas universitarios a través de los Centros Regionales de Educación Superior (CERES) y la formación ofrecida por el Servicio Nacional de Aprendizaje SENA.

Un papel protagónico debe cumplir la Universidad como eje articulador de los demás actores para lograr avanzar hacia el desarrollo. Fortalecer su actuación a través de alianzas ínter universitario e interinstitucional, sin duda resignificará su misión. La creación y fortalecimiento de Observatorios temáticos de los ODM en Pobreza, Hambre, Educación, Salud, Medio Ambiente, que analicen no solo aspectos cuantitativos, sino aspectos cualitativos, sociales, culturales y políticos de cada uno de ellos y la institucionalización de una cátedra de ODM liderados desde las Universidades son algunas de las propuestas. Se destaca en este sentido el esfuerzo y compromiso asumido por la Universidad Autónoma de Manizales, la Universidad de Caldas, la Universidad de Manizales, la Universidad Católica, la Universidad Luís Amigo, la Universidad Nacional de Colombia, la Universidad Cooperativa de Colombia, y el Servicio Nacional de Aprendizaje SENA, en alianza con el Programa de las Naciones Unidas para el Desarrollo (PNUD) para al desarrollo de la cátedra itinerante de los ODM, actividad académica que desarrolla desde Agosto y hasta Diciembre de 2008 y en forma simultanea en la ciudad de Pereira bajo el liderazgo de la Universidad Tecnológica de Pereira.

- Revalorar el rol estratégico del Estado y la política pública con relación al empoderamiento y la construcción de ciudadanía: fundamental dado que el logro de la metas del milenio depende de una responsabilidad compartida.

- Mejoramiento en el acceso y calidad de la Salud: componente fundamental del Capital Humano, requiere de una estrategia que incremente progresivamente la cobertura de la afiliación a la seguridad social en salud, tanto contributiva como subsidiada, promoviendo la focalización de los subsidios a las mujeres gestantes y a las mujeres en edad fértil, tanto en zonas rurales como urbanas. Paralelamente es necesario generar mecanismos adicionales para garantizar el acceso y la calidad de acuerdo con los estándares establecidos en las normas vigentes y la implementación de mecanismos de monitoreo de estándares de calidad.

Así mismo, son importantes: la normalización de la estrategia de vigilancia en salud pública, capacitación del recurso humano en el manejo operativo del modelo de vigilancia y las técnicas de investigación y análisis de muertes, promoción de la utilización de métodos anticonceptivos, mediante la inducción de la demanda, la eliminación de barreras de acceso y el seguimiento de su uso por parte de los servicios de salud, haciendo énfasis y adecuando su operación a las características y necesidades de la población adolescente.

Finalmente, se debe incrementar el acceso de la población a la toma y lectura de $\mathrm{VIH}$ Sida, citología cérvico-uterina, así como mejorar la adhesión de la mujer al esquema de detección precoz del cáncer de cuello uterino y a su tratamiento y el fortalecimiento de la vigilancia en salud pública en salud sexual y reproductiva, a través del diseño y disposición de metodologías estandarizadas de vigilancia sobre los eventos de interés y sobre el acceso y calidad.

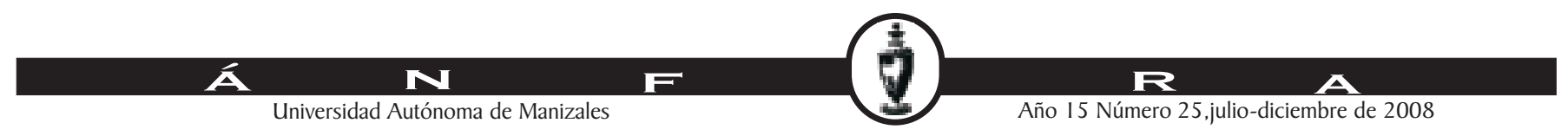




\section{Conclusiones y retos para Caldas.}

El Desarrollo Humano en Caldas, medido por el IDH, se muestra bajo con respecto al promedio nacional. Un crecimiento débil, no permite a los más pobres beneficiarse del mismo. Aproximadamente el $60 \%$ de la población está por debajo de la línea de pobreza y el $17 \%$ en indigencia. Adicionalmente, evaluar las brechas regionales, permitió concluir que el Alto Oriente presenta los mayores problemas de desarrollo humano y por lo tanto es prioritaria en la focalización de estrategias para avanzar hacia las metas.

Una estrategia para mejorar los índices de desarrollo humano en Caldas debe pasar por entonces: por aumentar el índice de longevidad, lo cual implica inversión en salud, saneamiento ambiental, especialmente acceso a agua potable, reducción de las tasas de criminalidad y gobernabilidad en las zonas con problemas de orden público y presencia de actores al margen de la ley, aumentar el índice de nivel educacional, reduciendo el analfabetismo y mejorando las tasas de escolarización especialmente a nivel secundaria y superior, y finalmente aumentando el PIB percápita.

Es necesaria la descentralización del departamento, la focalización de políticas subregionales y la búsqueda de un desarrollo socioeconómico más integral y equilibrado, basado en el fortalecimiento de sus subregiones a partir de la organización y participación de sus habitantes en la toma de decisiones que comprometen su futuro. Apostarle a la educación municipal, priorizando en los siguientes aspectos considerados en el Plan Decenal de Educación: vinculación del sector educativo con los demás sectores, incentivo a la investigación y la inclusión de las TIC's en las aulas, aprender a vivir en armonía, fomentar la ciencia y la investigación, acceso al conocimiento como requisito para un mundo global, dotación e infraestructura, calidad e inclusión en la educación inicial, aumento de coberturas, fomento de competencias ciudadanas, prevención de la deserción, fomento de la participación de los padres de familia como actores del proceso educativo, formación ética y en valores, mejoramiento de las condiciones de remuneración, evaluación y estímulo a la labor docente.

El acceso a la educación de los jóvenes entre los 5 y los 19 años debe garantizarse, así como su calidad y pertinencia. A nivel pedagógico la escuela debe dejar de implementar esquemas autoritarios centrados en el maestro para pasar a formar sujetos a partir de las necesidades e intereses de los alumnos como seres individuales y sociales en conexión con su entorno familiar y comunitario. Para que haya coherencia en la formación, los primeros a formar son los maestros y son las Universidades las llamadas a cumplir con esta misión social tan trascendente, entre otras, ofertando programas de formación a funcionarios y dirigentes públicos con suficientes elementos teóricos y herramientas para que puedan planificar acertadamente y con una visión de complementariedad de los territorios urbanos y rurales de sus municipios.

La generación de empleo de calidad, a partir de la promoción y fortalecimiento de los sectores primario y secundario en cada uno de los distritos, debe contribuir a reducir la pérdida de población calificada y no calificada, y mejorar las condiciones laborales de los ocupados para mejorar la competitividad del departamento.

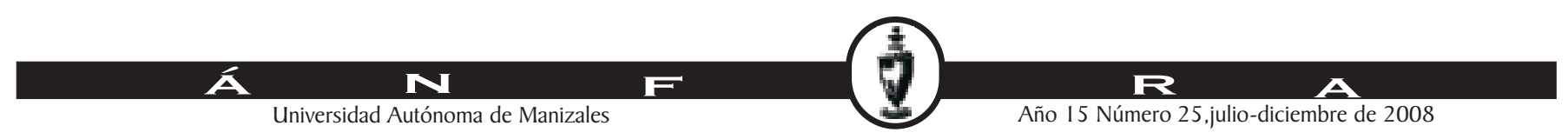


Finalmente, el carácter urbano del departamento obliga a fortalecer los procesos de ordenamiento y planeamiento territorial que garanticen el crecimiento ordenado y organizado de las ciudades en el marco de sus dinámicas urbano - rurales.

\section{Bibliografia.}

- PROGRAMA DE LAS NACIONES UNIDAS PARA EL DESARROLLO (PNUD); Universidad Autónoma de Manizales (UAM). 2008. Línea Base de los Objetivos del Milenio en Caldas - DIRECCIÓN TERRITORI AL DE SALUD DE CALDAS. Pefil epidemiológico. 2007. sp

- SUBDIRECCIÓN DE SALUD PUBLICA, grupo PAI. En: Cómo va la salud de Caldas. DTSC. Pobalción Ministerio de Protección Social.

- PAT 2007-2009. Corpocaldas.

- DNP, DANE, Gobernación de Caldas 2005.

- FEDERACIÓN ONGs de Caldas. Rendición social de cuentas 2006. 